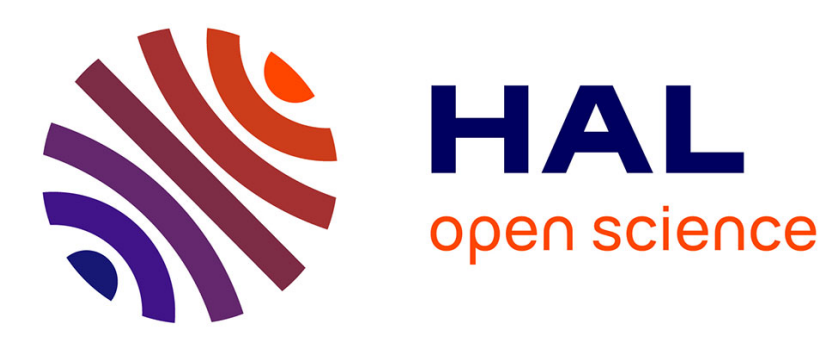

\title{
Zonal Detached-Eddy Simulation Applied to the Tip-Clearance Flow in an Axial Compressor
}

\author{
W. Riéra, J. Marty, L. Castillon, S. Deck
}

\section{To cite this version:}

W. Riéra, J. Marty, L. Castillon, S. Deck. Zonal Detached-Eddy Simulation Applied to the Tip-Clearance Flow in an Axial Compressor. AIAA Journal, 2016, 54 (8), pp.2377-2391. 10.2514/1.J054438 . hal-01397651

\section{HAL Id: hal-01397651 \\ https://hal.science/hal-01397651}

Submitted on 16 Nov 2016

HAL is a multi-disciplinary open access archive for the deposit and dissemination of scientific research documents, whether they are published or not. The documents may come from teaching and research institutions in France or abroad, or from public or private research centers.
L'archive ouverte pluridisciplinaire HAL, est destinée au dépôt et à la diffusion de documents scientifiques de niveau recherche, publiés ou non, émanant des établissements d'enseignement et de recherche français ou étrangers, des laboratoires publics ou privés. 


\title{
Zonal Detached Eddy Simulation applied to the tip clearance flow in an axial compressor
}

\author{
W. Riéra *, J. Marty ${ }^{\dagger}$, L. Castillon ${ }^{\ddagger}$, S. Deck ${ }^{\S}$
}

This paper presents the study of the tip clearance flow in an axial compressor using several turbulence modeling approaches: RANS (Reynolds averaged Navier-Stokes), URANS (Unsteady Reynolds averaged NavierStokes) and ZDES (Zonal Detached Eddy Simulation). Rotor simulations are carried out on the same mesh based on the ZDES requirements and compared to experimental data. ZDES brings significant improvements over RANS and URANS approaches to reach accurate integral values, especially the total pressure gradient prediction near the casing, as well as to capture complex flow patterns near the casing. While the URANS method predicts only tip leakage and induced vortices, the ZDES approach is able to reveal more complex phenomena as the tip leakage vortex, the contrarotative induced vortex and numerous secondary vortices are captured. Due to their interaction with the tip leakage vortex, secondary vortices roll-up around it. This leads to the generation of smaller vortices. The interaction between the tip-leakage vortices and the incoming stator wake, the latter being made up of the blade wake itself along with a tip vortex and a hub vortex, is evaluated and a tip-leakage vortex flutter phenomenon is detailed. A spectral analysis reveals a major difference between URANS and ZDES concerning the tip-leakage vortex disruption. The URANS approach dissipates the tip leakage vortex across the weak shock present at the blade tip and thus captures only the first three harmonics of BPF. On the contrary, with the ZDES method, the first ten harmonics are well captured and the

*Ph.D Student, Onera - The French Aerospace Lab, 8 rue des Vertugadins, 92190 Meudon, France, william.riera@snecma.fr, currently at SNECMA (SAFRAN Group).

${ }^{\dagger}$ Research Engineer, Onera - The French Aerospace Lab, 8 rue des Vertugadins, 92190 Meudon, France, julien.marty@onera.fr., Corresponding author

${ }_{\ddagger}^{\ddagger}$ Research Engineer, Onera - The French Aerospace Lab, 8 rue des Vertugadins, 92190 Meudon, France, lionel.castillon@onera.fr.

${ }^{\S}$ Research Engineer, Onera - The French Aerospace Lab, 8 rue des Vertugadins, 92190 Meudon, France, sebastien.deck@onera.fr. 


\section{tip leakage vortex further develops beyond the shock leading to a better prediction of velocity and pressure fluctuations.}

\section{Nomenclature}

$\begin{array}{ll}B P F & \text { Blade Passing Frequency of the IGV for Rotor } 1 \text { (R1) } \\ C & \text { Rotor } 1 \text { axial chord } \\ I G V & \text { Inlet Guide Vane } \\ L D A & \text { Laser-Doppler-Anemometry } \\ L E / T E & \text { Leading Edge / Trailing Edge } \\ R 1 & \text { Rotor } 1 \\ T & \text { Passage time period of IGV with respect to R1 } \\ (U) R A N S & \text { (Unsteady) Reynolds-averaged Navier-Stokes } \\ U_{i, j} U_{i, j} & \text { Velocity gradients: } \sum_{i, j}\left(\frac{\partial u_{i}}{\partial x_{j}}\right)^{2} \\ \Delta \mathrm{x}^{+}, \Delta \mathrm{y}^{+}, \Delta \mathrm{z}^{+} & \text {Normalized wall cell dimensions } \\ Z D E S & \text { Zonal Detached Eddy Simulation }\end{array}$

\section{Introduction}

In axial compressors, the gap between a rotating blade tip and the casing leads to a leakage flow from the pressure side to the suction side, as presented in figure 1. The interactions of this secondary flow with the main stream, the annulus boundary layer developing on the shroud and the blade wakes lead to penalizing losses, as seen by Herzig et al. ${ }^{1}$ The shear layer, which stems from the direction difference between the leakage flow and the main stream, is the main loss mechanism in the casing region. By contrast, the non-uniform mixing zone downstream the blade contributes a little to the whole pressure loss as underlined by Storer and Cumpsty. ${ }^{2}$ Therefore designing efficient compressors requires an accurate prediction of these phenomenatip leakage and vortical flows and interactions between them.

Based on experimental observations on a linear cascade, Bindon ${ }^{3}$ conceptualized the flow within the gap. He underscores that there is not a single flow pattern leaking through the gap. Instead of a linearly spread leakage, he hypothesized that there are different kinds of channels with and without separation bubbles within the gap. The axial position of these different channels depending on the pressure distribution along the chord, and thus the loading. Kang and Hirsch ${ }^{4,5}$ have experimentally investigated the tip leakage flow in a compressor cascade with a stationary endwall and the effect of tip gap size. The tip-leakage vortex starts to roll-up just downstream the leading edge inon the suction side. They pointed out that 


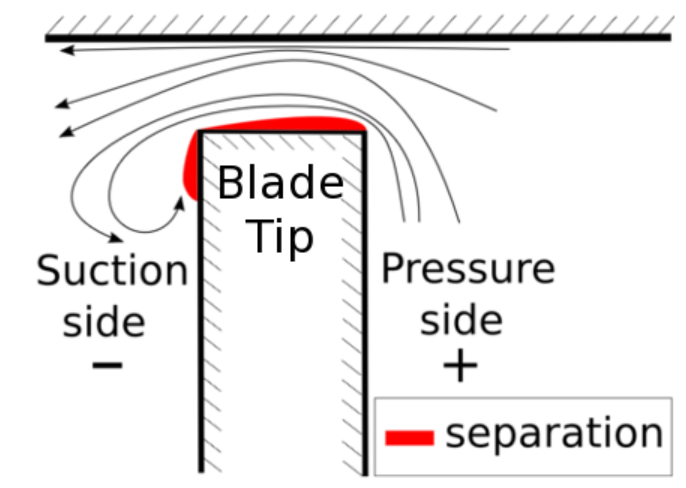

Figure 1. Tip-leakage flow in axial compressors.

streamlines in the gap are neither normal to the suction side nor to the camber line, contrary to what was assumed by Rains. ${ }^{6}$ They observed not only the tip-leakage vortex but two other vortices, the tip separation vortex located in the tip gap and coming from the pressure side and the secondary vortex resulting from the boundary layer separation on the suction side in the vicinity of the tip gap, as well. They also highlighted small horseshoe vortex in the front of the blade leading edge for small tip clearance. Suder and Celestina ${ }^{7}$ investigated experimentally and numerically the flow physics of the tip region of the transonic NASA Rotor 37, especially at design speed. They concluded that the strong interaction between the rotor passage shock and the tip leakage vortex generates a region of high blockage in the passage, which moves forward upstream and becomes larger in both the circumferential and radial directions as the rotor loading is increased. Moreover the shock/vortex interaction and ensuing blockage leads to high incidence angles at the blade tip, which may play a role in triggering tip stall. Thus the tip leakage flow is clearly three-dimensional and its accurate simulation is a challenge for computational fluid dynamics.

Mailach et $a l .{ }^{8}$ studied the interaction between periodically incoming stator wakes and the tip clearance vortex on the third rotor blade of the low-speed research compressor of Dresden. The trajectory of the tip vortex is modified and is very sinuous due to the vortex separation into several segments by wakes and to the appearance of counter-rotating vortices within the tip clearance vortex. Thus the incoming wakes modify the orientation and extension of tip vortices and the flow blockage at the tip periodically. It is important to take this effect into account in the simulation. So the current investigation deals with impact of incoming stator wakes on rotor tip leakage flow.

Reynolds-averaged Navier-Stokes (RANS) simulations, albeit widely used in the industry, do not predict accurately these unsteady flows. ${ }^{9}$ Large Eddy Simulation (LES) is more adapted to capture the vortices from the tip-leakage flow; ${ }^{10}$ however, its prohibitive cost 
to simulate high Reynolds number wall-bounded flows limits its actual use to academic low Reynolds number configurations. ${ }^{11}$ Hybrid RANS/LES methods, such as the Detached Eddy Simulation (DES), alleviate this constraint. The original DES version (DES97) ${ }^{12}$ uses the RANS method in the boundary layer and switches continuously to LES far from the walls in a zone called grey-area. If the mesh does not suit the DES requirements, this zone may be located in the boundary layer, resulting in an early switch to LES. Consequently, the velocity fluctuations from the LES do not balance the loss of the modelled Reynolds stresses. This phenomenon, known as Modelled-Stress Depletion (MSD) may lead to unphysical Grid Induced Separation (GIS). Spalart et al. ${ }^{13}$ presented an improved version of the original DES to prevent such separation. This method, called Delayed DES (DDES), detects the boundary layer with a sensor and solves it with a RANS approach. The Zonal Detached Eddy Simulation (ZDES), ${ }^{14}$ which is evaluated in this paper, is another solution and enables to select between RANS and different DES modes depending on the flow configurations of the studied case. Recent improvements of this zonal approach are presented by Deck. ${ }^{15}$ The DES modes, whose aim is to clarify the role of each region, are adapted to flows where the separation is fixed by the geometry, induced by a pressure gradient on a curved surface or strongly influenced by the dynamics of the incoming boundary layer. Thus it is flexible and suitable for simpleboth academic and industrial applications. Moreover, it was already applied to a wide panel of cases, from the simulation of an aircraft, ${ }^{16-19}$ to jet, ${ }^{20,21}$ and base flows, ${ }^{22,23}$ through the flow control applications ${ }^{24,25}$, the flow around a simplified launcher afterbody ${ }^{26}$ and the dynamic stall over rotorcraft airfoil. ${ }^{27,28}$ This method is also well-suited for wall bounded flows, especially for wall resolved LES $^{29}$ and wall modeled LES. ${ }^{23,30}$ The ZDES method is also implemented in other industrial CFD codes: in finite-element solver, ${ }^{31-33}$ in CAA solver ${ }^{34}$ as well as in an unstructured solver dedicated to multi-physics. ${ }^{35}$ The extensive validation of ZDES on both academic and industrial applications as well as implementation by independent teams in several industrial solvers are considered as milestones according to the maturity classification of model introduced by Rumsey et al. ${ }^{36}$

Yamada et al. ${ }^{37}$ numerically investigated with a Detached Eddy Simulation an axial compressor configuration with two different gap size values: $1 \%$ and $3 \%$. They found that the stall inception process differs depending on the clearance size. IndeedOn one hand, for the large tip clearance case, the stall inception process resulted from the vortex breakdown. By contrastOn the other hand, this is a spike-type stall inception in the case with the small gap. Riou ${ }^{9}$ studied the tip leakage flow prediction using Delayed Detached Eddy Simulation (DDES) on the experimental configuration of Muthanna and Devenport ${ }^{38}$ and Wang and Devenport. ${ }^{39}$ The purposes were to evaluate the numerical methods and analyze the effects of relative motion. The vortex disrupts earlier with the endwall motion. Moreover, he observed a secondary vortex in the moving endwall case. Besides, an elongation of the vortex 
core is captured too, and it bends towards the neighbouring blade. With no endwall motion, the vortex dilates but remains circular. The steps concerning the inception development and disorganisation of the vortex remains the same in the two cases. The tip leakage flow of a transonic compressor rotor was also investigated by Shi et al., ${ }^{40,41}$ especially the interaction between shock, tip leakage vortex and boundary layers. BesidesMoreover Greschner and Thiele ${ }^{42}$ analysed a 2.5D rotor-stator configuration with DDES and Improved DDES (IDDES) and highlighted clear improvements for wake and boundary layer simulations in IDDES.

The purpose of this paper is to evaluate the capability of the ZDES method to represent tip-leakage flows in comparison with RANS and URANS methods on a realistic rotor of high pressure compressor, in presence of incoming stator wakes.

\section{Experimental facility}

The studied configuration is the experimental compressor CREATE ${ }^{43,44}$ which is located at the Laboratory of Fluid Mechanics and Acoustics (LMFA) in Lyon, France. This axial compressor designed and built by SNECMA (Safran Group) comprises $3^{1 / 2}$ stages presented in figure 2 and is representative of the median and rear stages of modern high pressure compressors. The number of stages was chosen to have a magnitude of the secondary flow effects similar to a real compressor, and to be within the rig torque power limitation. The blade number for each row is detailed in table 1. The circumferential periodicity of the compressor CREATE has been reduced to $2 \pi / 16$. Consequently, measurements carried out over a sector of $22.5^{\circ}$ should contain all the spatial information for stabilized operating points at least and are very useful for rotor-stator interaction analysis.

In the present study, only the first rotor of the compressor (R1) is investigated at its design operating point, whose characteristics are summarized in table 2. Measurements are carried out with both pneumatic and unsteady pressure probes, detailed by Mersinligil, ${ }^{45}$ which are located in the axial sections $25 \mathrm{~A}$ and $26 \mathrm{~A}$, visible in figure 2. To have traversal probes between blade and vane rows, the axial gap was slightly increased compared to current compressors, and an euter-easeouter-casing moving-rings technology was implemented to perform probe measurements in the circumferential direction at constant radius.

Table 1. Blade number for the rows

\begin{tabular}{|c|c|c|c|c|c|c|c|}
\hline Row & IGV & R1 & S1 & R2 & S2 & R3 & S3 \\
\hline Blade number & 32 & 64 & 96 & 80 & 112 & 80 & 128 \\
\hline
\end{tabular}




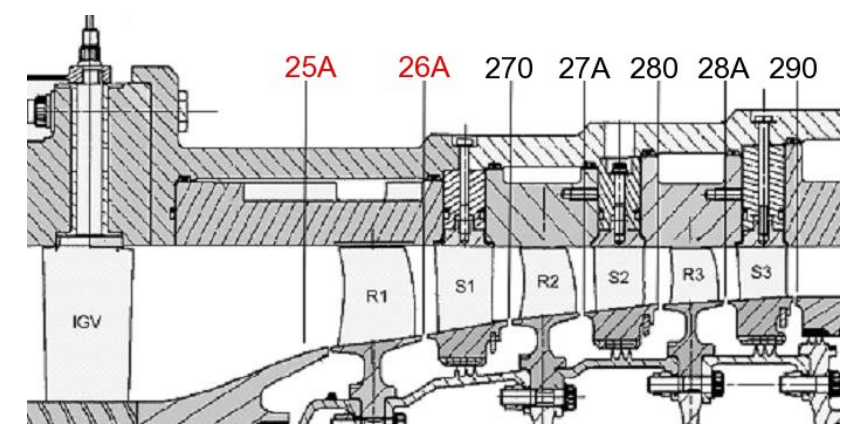

Figure 2. CREATE compressor meridian view.

Table 2. Characteristics at design operating point

\begin{tabular}{|c|c|}
\hline Outer casing diameter & $0.52 \mathrm{~m}$ \\
\hline Rotating speed & $11543 \mathrm{rpm}$ \\
\hline Mass flow & $12.7 \mathrm{~kg} . \mathrm{s}^{-1}$ \\
\hline Inlet Mach number at tip of R1 & 0.92 \\
\hline
\end{tabular}

\section{Numerical method}

\section{III.A. Computational domain and grid description}

In the following presented configurations, only the first rotor of the compressor (R1) is modelled. Indeed, modelling the IGV would increase the cost of the study. Instead, specific inlet conditions are applied to take into account the IGV effects as detailed in section III.C. The inlet boundary of the test bench is set to section 25A of the experimental test rig, located between the IGV and the R1. The reason is that measurements are available on the experimental compressor for different operating points at this section. Besides, the possible comparisons with experimental data at section 25A make the numerical setup more reliable for the evaluation of the method. The location of the outlet boundary is based on the hypothesis that the outflow is axisymmetric, therefore, it must be far from the trailing edge of the R1. Furthermore experimental measurements are available at section 26A, so this section has to be inside the computational domain for validation purposes. Nonetheless, the mesh size is a key element in the domain definition. This is why the outlet boundary of the computational domain is defined at two axial chords downstream the R1.

An important aspect of this study is the fact that the numerical methods RANS, URANS and ZDES are evaluated on the same mesh. The grid suits the ZDES requirements and is obtained with a multi block approach using an $\mathrm{O} 4 \mathrm{H}$ topology. Each passage is meshed with an $\mathrm{O}-\mathrm{H}$ strategy. O blocks are used around the blades and $\mathrm{H}$ blocks fill the rest of the passage. Finally, the rotor tip clearance is meshed with an additional O-H block. 
The zonal approach affects the mesh refinement as follows: a RANS type mesh upstream of the blade, and DES type mesh from the leading edge onward, i.e. a LES resolution mesh except on the wall. The normalized wall cell dimension normal to the wall fulfils $\Delta \mathrm{y}^{+}$of the order of 1 in every zone. However, its wall parallel counterparts differ depending on the zones: upstream of R1, $\Delta \mathrm{x}^{+}$(streamwise direction) is between 400 and 500 and $\Delta z^{+}$(spanwise direction) less than 100; in the vicinity of the blades, $\Delta \mathrm{x}^{+}$and $\Delta \mathrm{z}^{+}$are respectively of the order of 200-300 and 100; and downstream of the blades, the mesh is progressively coarsened to 1700 for $\Delta \mathrm{x}^{+}$and 150 for $\Delta \mathrm{z}^{+}$so as to avoid numerical reflections. The computational domain is shown in figure 3 . The whole grid comprises $\mathrm{N}_{\mathrm{xyz}}=88$ million points in order to model 1/32 of the compressor, i.e. two channels of R1, which corresponds to the inlet guide vane blade count. Note that a Wall Resolved Large Eddy Simulation (WRLES) would require a larger grid by a ratio of $\frac{\left(\Delta x^{+}\right)_{\text {present }}\left(\Delta z^{+}\right)_{\text {present }}}{\left(\Delta x^{+}\right)_{\text {WRLES }}\left(\Delta z^{+}\right)_{\text {wrLeS }}} \approx \frac{300}{50} \frac{100}{15}=40$ i.e. $\mathrm{N}_{\mathrm{xyz}}>3.510^{9}$ points.

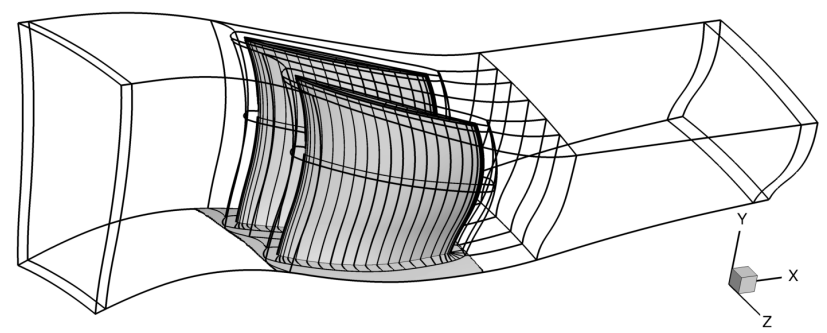

Figure 3. Computational domain for the calculations on the first rotor of CREATE.

\section{III.B. CFD Solver}

The CFD solver used in this study is the ONERA's software els $A,{ }^{46}$ which is based on a cell centred finite volume approach to solve the Navier-Stokes equations on a structured multi-block grid. The computation is performed in the rotor frame of reference. The casing wall is then moving regarding this relative frame. The spatial discretization scheme ${ }^{47}$ for the inviscid fluxes is based on the third order accurate Advection Upstream Splitting Method for low Mach numbers (AUSM+P), initially developed by Edwards and Liou. ${ }^{48}$ A classic second order centred formulation is used for the viscous fluxes. All these numerical schemes are common to the three methods compared in the present study: RANS, URANS and ZDES.

\section{III.B.1. Steady and unsteady Reynolds-averaged Navier-Stokes simulations}

The steady RANS computation is carried out with the Spalart-Allmaras ${ }^{49}$ turbulence model. The time discretization scheme is the implicit backward-Euler method. The unsteady RANS computation is based on the same turbulence model. However, time integration is based on the second order accurate Gear scheme. At each time step, an approximate Newton method 
based on the LU factorization solves the non-linear problem. The time step is set to $1.610^{-7} \mathrm{~S}$ which leads to a Courant-Friedrich-Levy number lower than 1 except for the boundary layers. It corresponds to 1000 time steps per IGV passing period. The use of 8 sub-iterations per time-step is required to reach a decay superior to one order of magnitude for the residuals. This criteria is a compromise between precision and cost of the computation and takes into account the small time step involved..$^{50}$

\section{III.B.2. Zonal Detached Eddy Simulation}

Concerning the ZDES computation, time and space integrations, as well as the time step are identical to the URANS one. Moreover, the ZDES version used in this study is based on the Spalart-Allmaras RANS model. The ZDES modifies the distance to the wall $d_{w}$ in the transport equation of the pseudo viscosity $\tilde{\nu}$, defined by Spalart and Allmaras, ${ }^{49}$ by $\tilde{d}_{Z D E S},{ }^{15}$ the ZDES length scale. Depending on the DES mode chosen for each zone, $\tilde{d}_{Z D E S}$ reads as equation (1):

$$
\tilde{d}_{Z D E S}= \begin{cases}d_{w} & \text { if mode }=0 \\ \tilde{d}_{D E S}^{I} & \text { if mode }=1 \\ \tilde{d}_{D E S}^{I I} & \text { if mode }=2 \\ \tilde{d}_{D E S}^{I I I} & \text { if mode }=3\end{cases}
$$

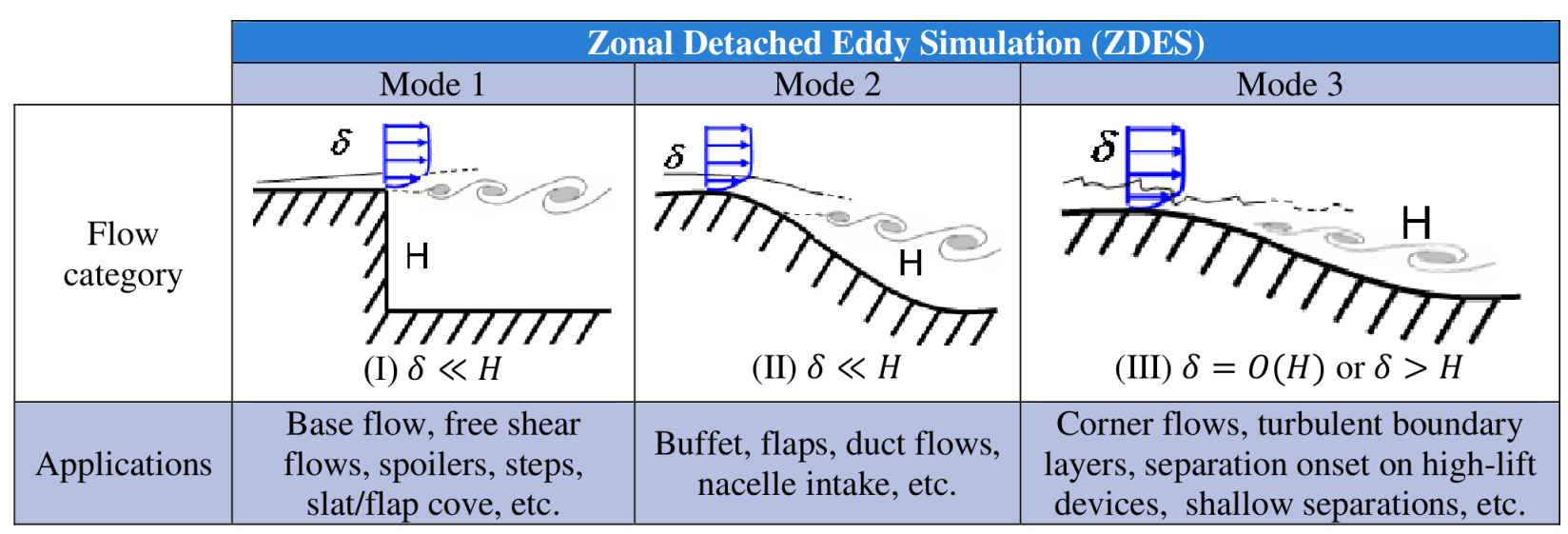

Figure 4. Classification of typical flow problems. I: separation fixed by the geometry, II: separation induced by a pressure gradient on a curved surface, III: separation strongly influenced by the dynamics of the incoming boundary layer (adapted from Deck $^{15}$ ).

The mode $=1$ of the ZDES is adapted to configurations where the separation is fixed by the geometry, figure 4 (left), and $\tilde{d}_{D E S}^{I}$ is equal to $\min \left(d_{w}, C_{D E S} \Delta_{v o l}\right)$ with $\Delta_{v o l}=$ $\sqrt[3]{\Delta_{x} \Delta_{y} \Delta_{z}} \cdot C_{D E S}=0.65$ is a constant for the DES which was defined by Shur et al. ${ }^{51}$ 
The mode $=1$ of the ZDES differs from the DES97 in its use of a length scale based on the volume $\Delta_{v o l}$, instead of the maximum length of the cell $\Delta_{\max }=\max \left(\Delta_{x}, \Delta_{y}, \Delta_{z}\right)$. It differs also by the removal of the wall-functions in mode $=1$ in order to avoid modelled-stress depletion.

The mode $=3$ corresponds to a wall-modelled LES i.e. the boundary layer is resolved in LES. ${ }^{18,23,52}$ It suits cases where separation is highly dependent on the dynamics of the incoming boundary layer, figure 4 (right). It is based on $\tilde{d}_{D E S}^{I I I}$ which is equal to $\tilde{d}_{D E S}^{I}$ if distance to the wall $d_{w}$ is higher than $d_{w}^{\text {interface }}$ and otherwise is equal to $d_{w}$. Thus $d_{w}^{\text {interface }}$ is the distance to the wall over which the model switches to a LES mode. In this LES mode, the near-wall functions in the transport equation of the pseudo viscosity of the DES model are removed as in the first mode. Moreover, a modified synthetic eddy method is implemented to generate the turbulent field. ${ }^{53}$ The mode $=3$ is not used in the present study.

The mode $=2$ suits cases where the separation is unknown a priori and induced by a pressure gradient on a curved surface, figure 4 (middle), hence its implementation around the blades and in the tip gap. It is based on $\tilde{d}_{D E S}^{I I}$ which is defined by:

$$
\tilde{d}_{D E S}^{I I}=d_{w}-f_{d} \cdot \max \left(0, d_{w}-C_{D E S} \tilde{\Delta}_{D E S}^{I I}\right)
$$

where $f_{d}=1-\tanh \left[\left(8 \frac{\nu+\nu_{t}}{\sqrt{U_{i, j} U_{i, j}} \kappa^{2} d_{w}^{2}}\right)^{3}\right]$ is the original DDES function ${ }^{54}$ designed to be equal to zero in boundary layer and 1 elsewhere. $\tilde{\Delta}_{D E S}^{I I}$ is the subgrid length scale entering the mode 2 of ZDES:

$$
\tilde{\Delta}_{D E S}^{I I}= \begin{cases}\Delta_{\max } & \text { if } \quad f_{d} \leq f_{d 0} \\ \Delta_{\text {vol }}\left(\text { or } \Delta_{\omega}\right) & \text { if } \quad f_{d}>f_{d 0}\end{cases}
$$

where $f_{d 0}=0.8$. Unlike DDES/DES97 where $\Delta$ is defined as the largest of the spacing in all directions, $\tilde{\Delta}_{D E S}^{I I}$ depends also on the flow solution, namely the velocity and eddy viscosity fields. It is important to emphasize that the shielding of the boundary layer is still ensured by equations (2) and (3) which behaves as standard DES $\left(\tilde{\Delta}_{D E S}^{I I}=\Delta_{\text {max }}\right)$ as long as $f_{d} \leq f_{d 0}$. The improvement lies in $\Delta_{v o l}$ (or $\Delta_{\omega}$ ) becoming the new subgrid length scale when $f_{d}>f_{d 0}$ which solves the problem of delay in the formation of instabilities.

The zonal configuration is presented in figure 5. The upstream domain is defined with mode $=0$, in red, while DES modes are set to the other zones. Both mode $=1$, in blue, and mode $=2$, in green and black for the tip gap, are used in the DES part of the ZDES computation.

The choice of mode $=0$ in the inlet region is due to the will to avoid artificial generation of turbulence for the inlet boundary condition. Indeed, as the value for $\tilde{\nu}$ is extracted from the preliminary study, it is a reliable quantity contrary to what is imposed with an artificial 


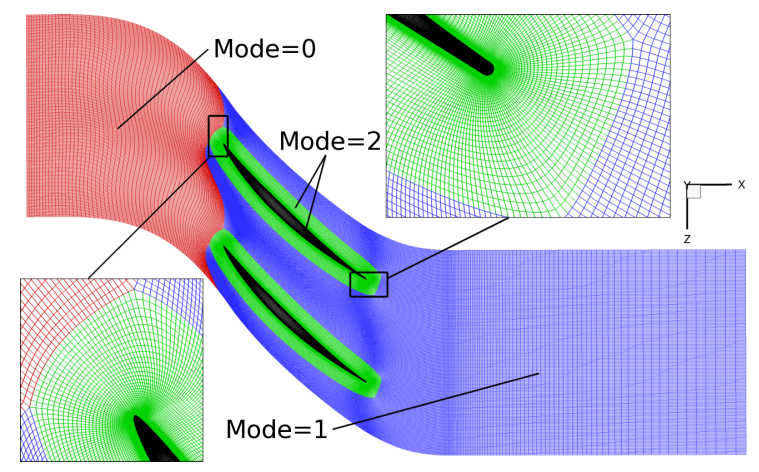

(a) Blade to blade view.

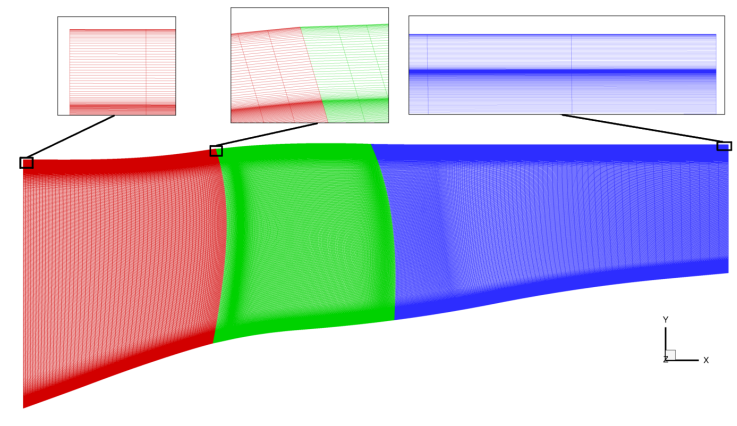

(b) Meridian view.

Figure 5. Mesh configuration for the ZDES modes on Rotor 1 of CREATE. Red: mode $=0$. Blue: mode $=$ 1. Green: mode $=2$. Black (tip gap mesh) $:$ mode $=2$.

generation of turbulence, such as the synthetic eddy method (SEM). Besides, mode $=0$ is the mode to favour when the boundary layers are attached.

Concerning the flow around the blade, both modes 1 and 2 are used. These two modes relate to the DES modes of the ZDES method and are very different as previously shown. In the present study, mode $=1$ is defined in every zone from the axial position of the $\mathrm{O}$ mesh of the row, except the $\mathrm{O}$ mesh and gap mesh. Indeed mode $=1$ is close to the standard DES mode, except in the definition of the subgrid length and near wall function treatment enabling a rapid switch from RANS to LES, and LES content is expected in these regions, especially downstream the blade. These regions are not on curved surfaces and are not subject to strong pressure gradient. Around the blades and in the tip gap, mode $=2$ is used. The choice of mode $=2$ in the vicinity of the blade is direct since it is typically the kind of configuration the method has been developed for. Indeed, the blade is a curved surface with a strong pressure gradient. Nevertheless, the choice of mode $=2$ for the tip gap needs to be explained thoroughly. The tip-leakage region is a complex area driven by two main flows. On the-one hand the main flow goes in the axial direction, on the other hand the leakage flow goes in the circumferential direction. If the leakage flow only is considered, it seems natural to use the mode $=1$ of the ZDES since the separation is clearly imposed by the geometry. However, this is without taking into account the influence of the main flow on the tip vortex topology. This would change completely the flow topology computed near the shroud, and therefore lead to important prediction errors concerning the position and direction of the vortex. Thereby, mode $=2$ is chosen in order to protect the boundary layer on the suction side of the blade by forcing the RANS mode in it as this strategy avoids from grid induced separation. This shows the different conflicting requirements expected for a hybrid model to simulate such kind of flow and ZDES allows such a flexibility in the turbulence treatment. 


\section{III.C. Boundary conditions}

In order to determine the inlet boundary condition for the isolated R1 configuration, a preliminary steady calculation of the Inlet Guide Vane (IGV) and R1 has been performed. It aims at capturing the wake of the IGV. The support struts upstream the IGV are not taken into account in all these computations.

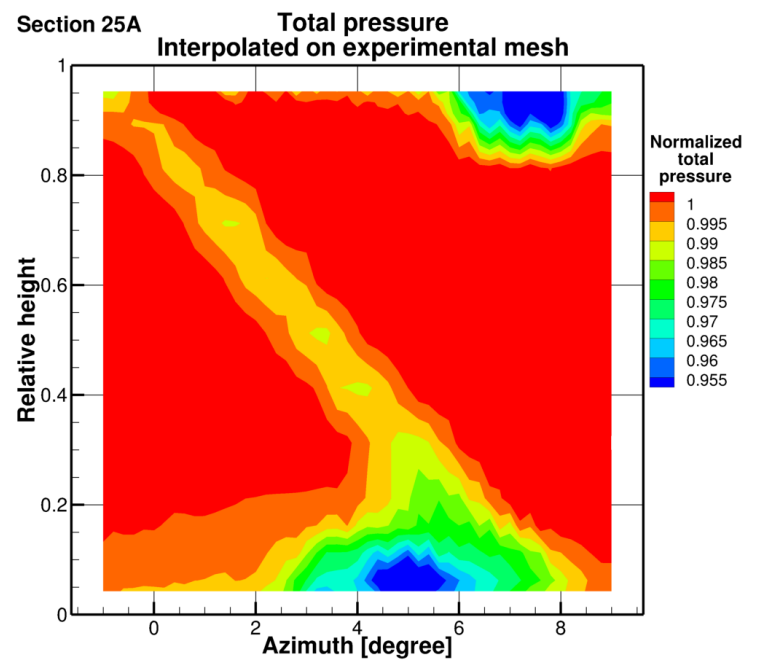

(a) RANS results, Spalart-Allmaras turbulence model with curvature correction and AUSM+P

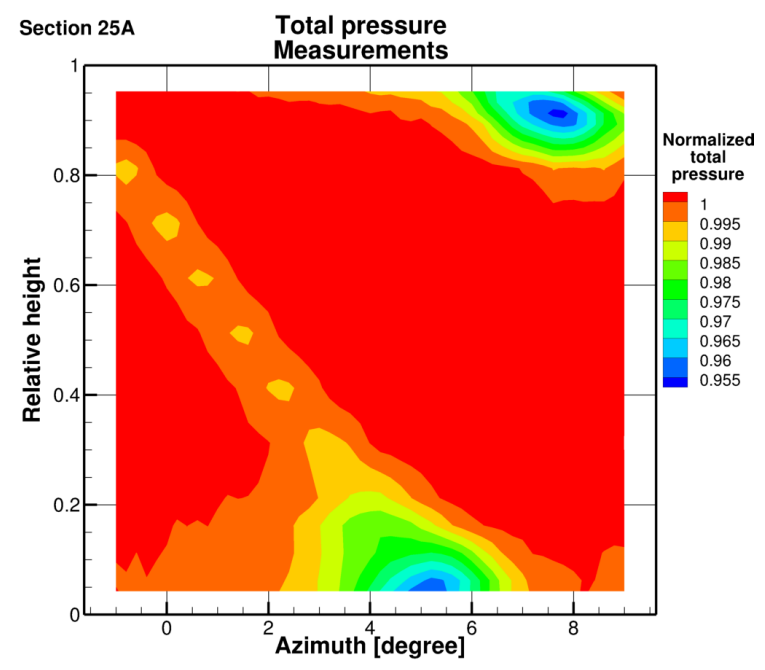

(b) Experimental data

Figure 6. Total pressure at section 25A.

This IGV-R1 computation simulates one channel of the compressor with a mixing plane located downstream section $25 \mathrm{~A}$. The mesh respects requirements for a fine RANS computation and thereby comprises 7.3 million points for one channel of the IGV and one of the R1. The turbulence model is Spalart-Allmaras with curvature correction (SARC). ${ }^{55}$ The spatial integration scheme is the AUSM $+\mathrm{P}$ and the implicit backward-Euler method is applied. The IGV has a variable stagger and therefore tip and hub gaps, which are approximated for the study. This induces tip and hub vortices in addition to the classic IGV wake. Nevertheless, the computation succeeds in the capture of the IGV effects at section 25A. This is highlighted by the total pressure maps at section 25A, in figure 6(a) for the CFD results interpolated on the experimental mesh, and in figure 6(b) for the pneumatic probe measurements. The position of the IGV hub vortex (azimuth 4-6, relative height 0-0.1), the IGV tip vortex (azimuth 7-8, relative height 0.9-1) and the IGV wake match the measurements, although it tends to minimise the azimuthal shift of the hub and tip vortices and decrease the total pressure of these phenomena as shown by the total pressure radial distribution in figure $7(\mathrm{a})$. The back pressure used at the outlet via a radial equilibrium law has been adapted to match the probe measurements at the tip in terms of axial momentum. Nonetheless, there is still an under-estimation of $3 \%$ in the capture of the IGV hub vortex axial momentum, visible in 


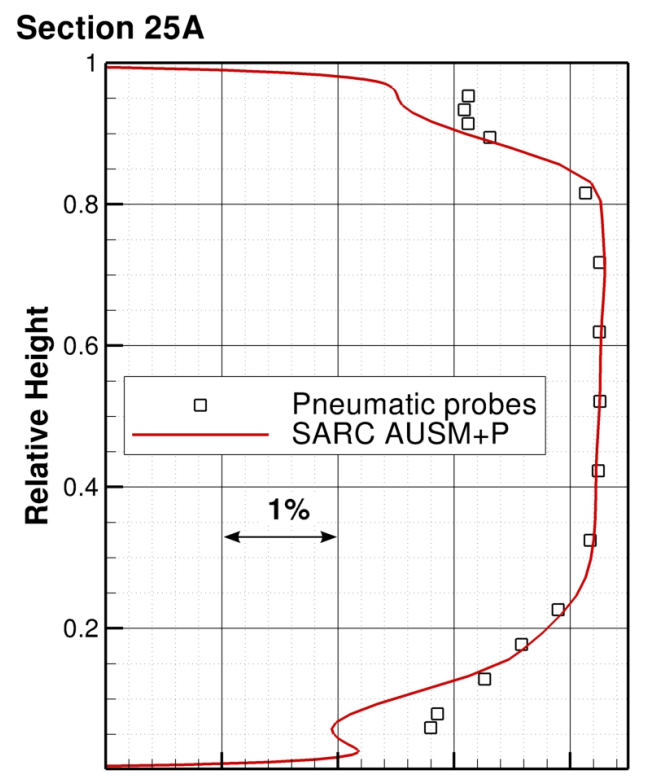

Total pressure

(a) Total pressure distribution

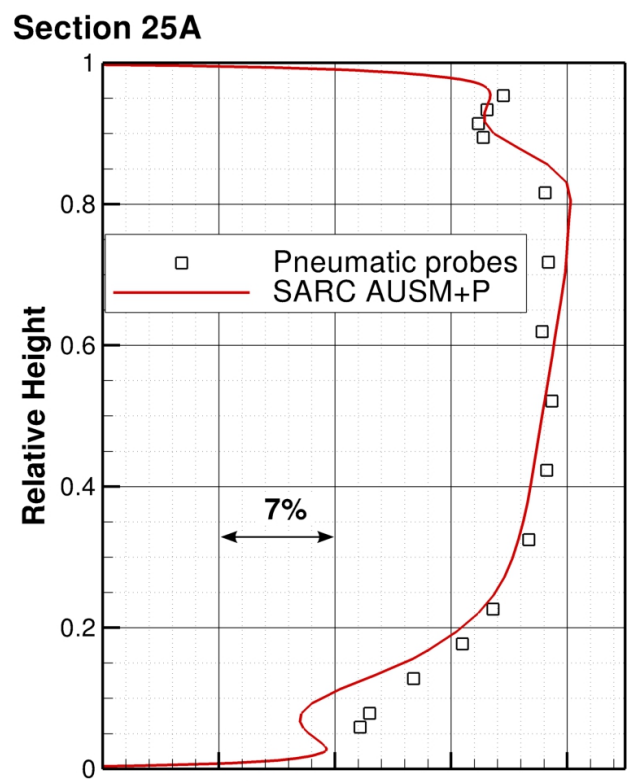

Axial momentum

(b) Axial momentum distribution

Figure 7. Radial distributions at section 25A, RANS results and pneumatic probes.

the radial distribution, in figure $7(\mathrm{~b})$.

The resulting map at $25 \mathrm{~A}$ of the IGV-R1 computation is used to generate the inlet condition for the computations on R1. Located at section 25A, it consists in a rotating distortion cartography, whose method was used for centrifugal compressor by Tartousi et al. ${ }^{56}$ based on a Fourier decomposition with 60 harmonics of the two dimensional map of the flow. The boundary condition used at the upstream is a subsonic inlet condition. The values for stagnation pressure, stagnation enthalpy, primitive turbulence quantity of the model, and direction of the flow are given at each cell center of the map. Since the Spalart-Allmaras model, which is used in the preliminary study, is consistent with the turbulence model used in the ZDES method, the turbulence value, $\rho \tilde{\nu}$, can be directly extracted from the cartography. These imposed values can either be steady (constant during the computation), or unsteady (they vary at each time step). In the present case, the imposed values vary as a function of time, since the rotor rotates in front of a steady 2D map corresponding to the outlet of the IGV. Therefore, at each time step, the imposed values are first of all interpolated from this 2D map. Once the values are determined, the injection condition consists in solving the Characteristic equation $\left(p+\rho c V_{n}\right)_{\text {boundary }}=\left(p+\rho c V_{n}\right)_{\text {cell }}$ where $p, \rho, c$ and $V_{n}$ are the static pressure, the density, the sound speed and the normal velocity component respectively. This equation states that Riemann invariants $\left(p+\rho c V_{n}\right)$ at the boundary (unknown values which are to be determined) are equal to their values in the adjacent computational cell (which are 
known). Plugging into this equation the imposed values which have been detailed (stagnation pressure, stagnation enthalpy, ...), this equation can be transformed into an equation where the unknown is the magnitude of the velocity (its direction being known). In particular, one uses the relationship $p=P_{i}\left(1-U^{2} /\left[2 H_{i}\right]\right)^{(\gamma /(\gamma-1))}$ where $P_{i}, H_{i}$ and $U$ are the stagnation pressure, the stagnation enthalpy and the velocity magnitude respectively, leading to an equation where the velocity magnitude is the unknown of a non linear system which is solved by a Newton method (a few iterations are necessary to reach the solution). With this rotating boundary condition, the unsteady distortion effects induced by the IGV are modelled in the simulation of R1 flow. For the stationary computation, the two dimensional map is azimuthally averaged. The effect of inlet condition is investigated by Riéra et al. ${ }^{57}$ with ZDES.

For the outlet boundary condition, the static pressure is specified at the hub and then a simplified radial equilibrium law, defined by equation (4), is applied. The three following computations use the same static pressure value, which is chosen to match the axial momentum, as in figure 7(b). It should be noticed that the first stator S1 effects (e.g. potential effects) are not taken into account in the present investigation.

Finally, a classic rotation periodicity condition is set at the azimuthal boundaries.

$$
p(r)=p_{h u b}+\int_{r_{h u b}}^{r}\left[\frac{\rho U_{\theta}^{2}}{r}\right] d r \quad p_{h u b}=p\left(r_{h u b}\right)
$$

\section{III.D. Validity of ZDES mode distribution}

Before analyzing the numerical results, the distribution of ZDES modes must be validated and the RANS and LES areas highlighted. Figure 8 represents the instantaneous fields of entropy variation, as the absolute value of entropy is always arbitrary, and eddy viscosity from the ZDES computation in the vicinity of the blade tip. The entropy variation $\Delta s$ is defined by:

$$
\Delta s=C p \ln \left(\frac{T s}{T s_{\text {ref }}}\right)-r \ln \left(\frac{P s}{P s_{\text {ref }}}\right)
$$

where the reference state is taken at the computational domain inlet. The ratio of the turbulent and laminar viscosity coefficients distinguishes the LES zones, which have a low turbulent viscosity from the RANS ones, with a higher value. Three axial planes at sections $22 \%, 31 \%$ and $46 \%$ of the blade axial chord $(\mathrm{X} / \mathrm{C})$ are displayed. Their positions along the chord are indicated in figure 9. When adiabatic wall conditions are used, zones of entropy creation correspond to zones of loss of stagnation pressure as explained by Denton. ${ }^{58}$ In the tip region, these losses stem mainly from the boundary layers and from the mixing between the clearance jet and the main flow, leading to the tip-leakage vortex. As a result, the entropy variation field is used to observe the tip-leakage vortex and boundary layers over 
casing, blade tip and blade suction side. In addition of the instantaneous flow fields, isolines of the $f_{d}$ function are overlaid. The $f_{d}$ function, defined in section III.B.2, is a sensor for the boundary layer used in the ZDES. Its value is inferior to 1 in the boundary layer. In mode 2 only, this $f_{d}$ sensor detects the boundary layer and aims at protecting it by forcing the RANS method in this region. Nevertheless, since this transition is continuous, the location of the transition region between RANS and LES is not accurate. However, the value 0.99 of the $f_{d}$ sensor, which is represented in the figure, can be used to differentiate the zone regarded as a boundary layer from the outer region within the mode $=2$. Along the chord,

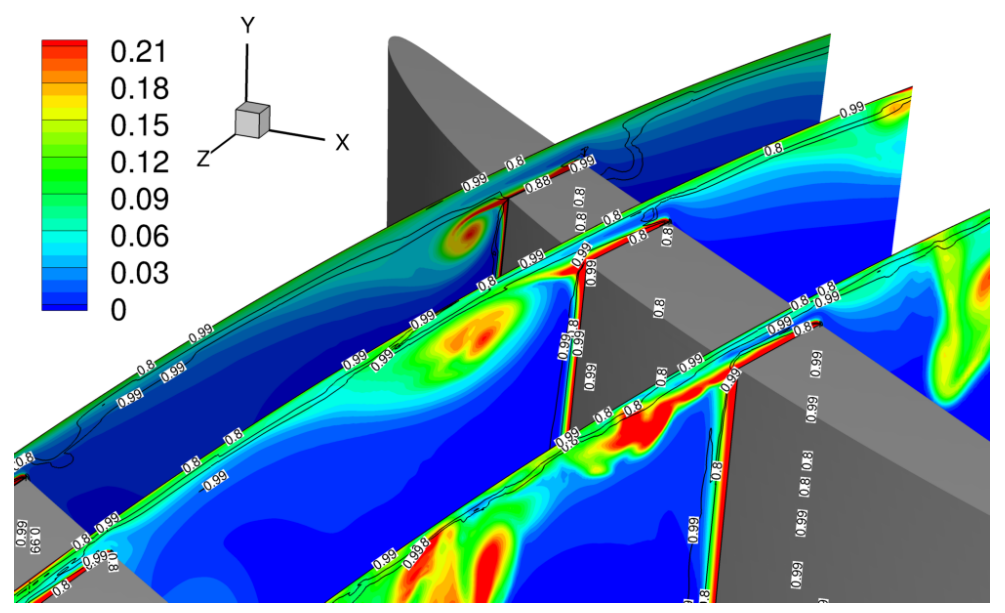

(a) Entropy variation $\Delta s$.

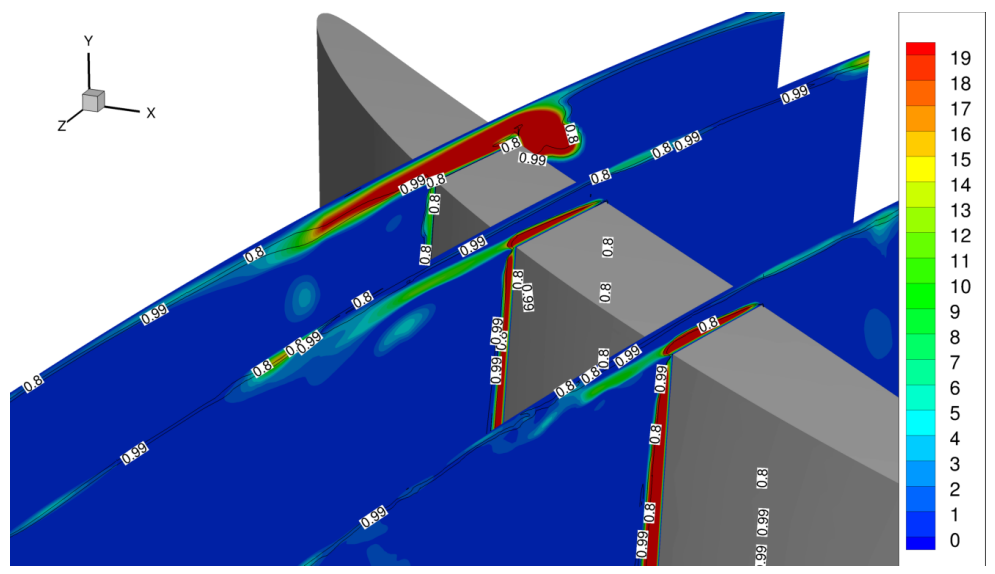

(b) Instantaneous eddy viscosity $\mu_{t} / \mu$.

Figure 8. Instantaneous entropy variation and eddy viscosity axial planes with isolines of $f_{d}$ sensor. From left to right : sections $22 \%, 31 \%$ and $46 \%$ X/C. Tip region from the ZDES computation.

the boundary layer developing on the walls is simulated in RANS, which is expected due to the forcing in mode $=2$ in these regions in the vicinity of the blade. The boundary layer developing on the suction side grows and is still simulated in RANS. Nevertheless, the tip gap zone is more complex due to the casing and blade tip boundary layers. Actually, the whole gap zone is computed with RANS or RANS and LES depending on the axial position. 


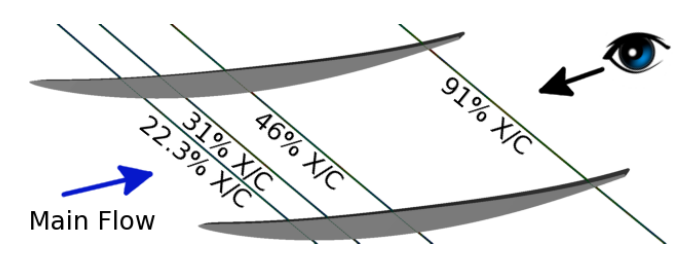

Figure 9. Position of the visualisation planes.

Upstream section $31 \% \mathrm{X} / \mathrm{C}$, the tip gap is fully resolved in RANS. The reason is the thick boundary layer which comes from the leading edge of the blade and contaminates the whole gap. It is even thicker on the edge between the pressure side and the tip, as visible at section $22 \% \mathrm{X} / \mathrm{C}$. By contrast, from section $33 \% \mathrm{X} / \mathrm{C}$ onward, the tip gap is resolved with both RANS and LES. There is still the RANS mode in the boundary layers due its protection by mode $=2$, but between the boundary layer developing on the blade tip and the one developing on the casing, there is a thin zone in LES. The resolution in RANS of the tip gap near the leading edge is a limitation of the RANS/LES approaches based on the DES, but this behaviour was expected. The tip gap size regarding the boundary layer thickness is an important parameter to take into account when DES-type methods are used. Indeed, if the boundary layer is thicker than the gap size, the gap region will be resolved in RANS. This is partly the case in this study, at least near the leading edge. Despite this limitation, the formation and development of the tip-leakage vortex is correctly computed in the LES mode of the ZDES. The vortex formation and widening can be seen in figure 8(a) on the suction side. Their computation in LES is a positive aspect of using the ZDES method for the simulation of the tip-leakage flow. This behaviour is the one that is expected since the leakage jet flow is clearly a "detached" flow, computed in LES. As a consequence, the ZDES behaves correctly for the simulation of the tip leakage flow.

\section{Results and discussions}

\section{IV.A. Tip flow analysis}

\section{IV.A.1. Time-averaged flow}

It is important to put this study into perspective towards the previous analysis on the tipleakage flow done in the literature. Two dimensionless criteria are used for the study of tip clearance flow topology. The first one is $\lambda=\frac{\text { GapSize }}{\text { MaximumBladeThickness }}$, the dimensionless tip clearance size with respect to the maximum blade thickness. In the first rotor of the CREATE compressor, its value is 0.23 . Following the analysis from Rains ${ }^{6}$ since $\lambda$ is superior to 0.026 , a vortex structure is expected. Moreover, Rains defined then the factor $\lambda^{2} \cdot R e \cdot \epsilon$, with $R e$ the Reynolds number based on the free stream velocity, and $\epsilon$ the maximum thickness to chord 
ratio, so as to generalize the tip-leakage flow topologies. For the $\mathrm{R} 1, \lambda^{2} \cdot R e \cdot \epsilon$ is clearly in the domain defined by Rains ${ }^{6}$ where the inertia forces are predominant over the viscous forces, mainly due to the high Reynolds number. As a consequence, the topology is mainly driven by the potential flow pressure distribution in the R1 of CREATE. The second criterion is the dimensionless tip clearance size with respect to the axial chord length, $\tau=\frac{\text { GapSize }}{\text { AxialChord }}$. For the R1, the value for $\tau$ is $1.75 \%$. By comparing with the previous experimental studies on different tip clearance sizes from Brion, ${ }^{59}$ the expected topology with this $\tau$ value is a tip-leakage vortex that remains close to the casing while being convected away from the blade suction side. The time-averaged entropy variation, normalized helicity and relative

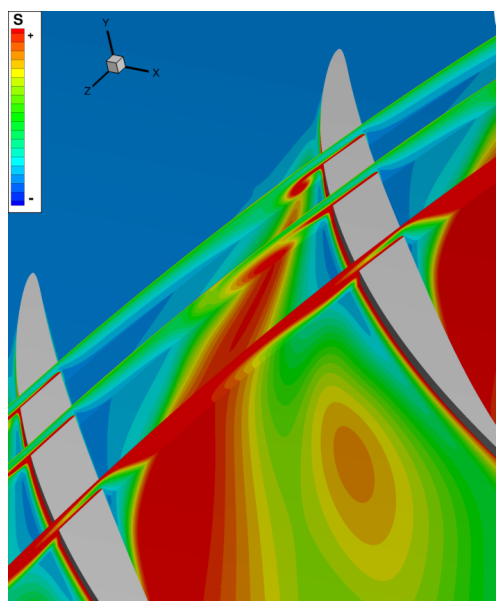

(a) URANS - Entropy variation $\Delta s$

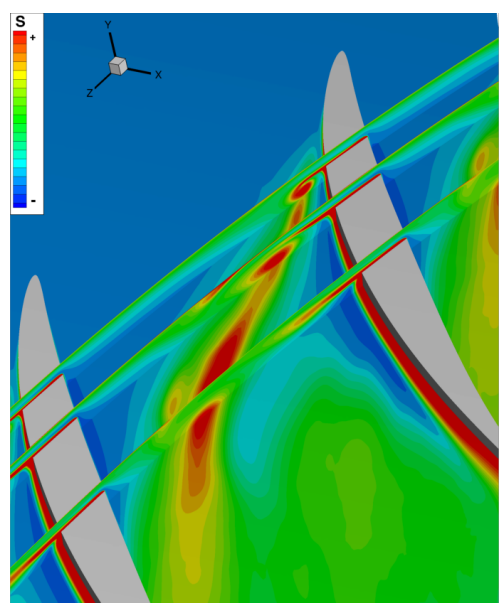

(d) ZDES - Entropy variation $\Delta s$

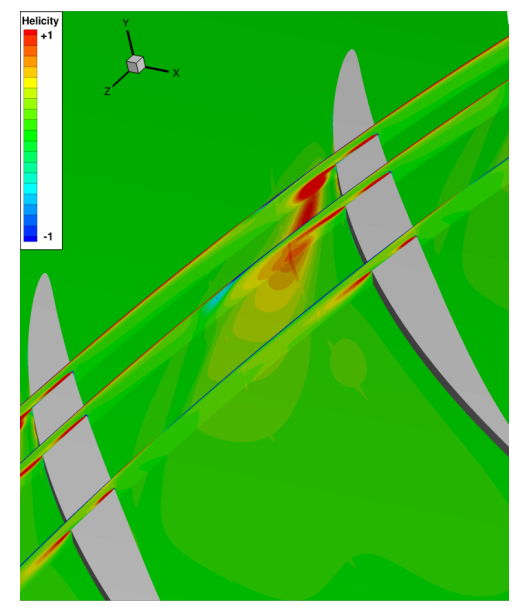

(b) URANS - Helicity

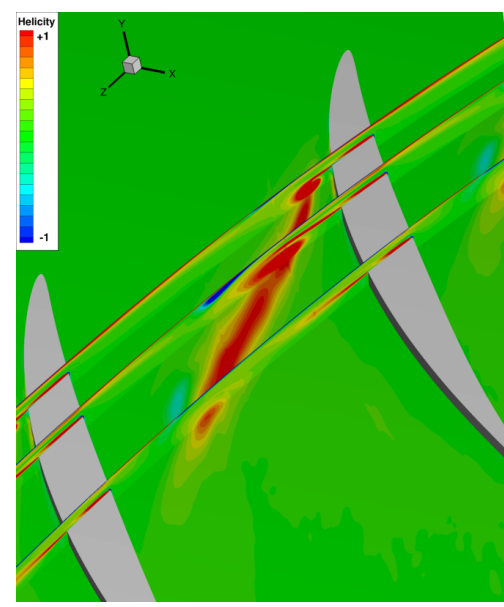

(e) ZDES - Helicity

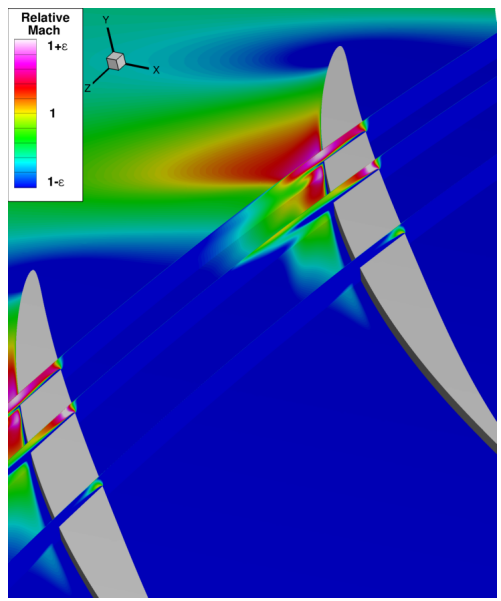

(c) URANS - Relative Mach number

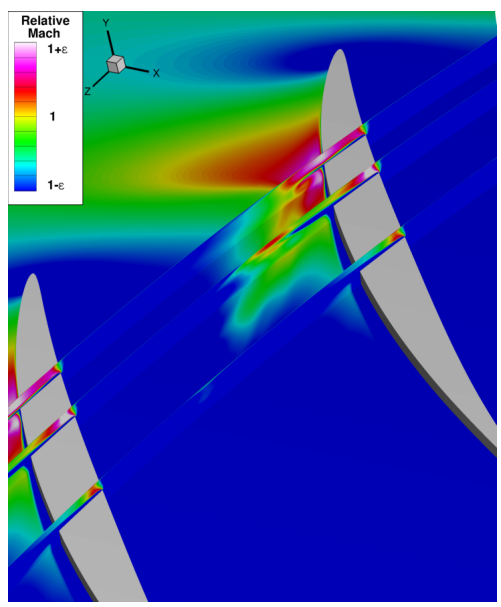

(f) ZDES - Relative Mach number

Figure 10. Comparison of the time averaged fields of entropy variation (a, d), normalized helicity (b, e) and relative Mach number (c, f) of URANS (a-c) and ZDES (d-f). Entropy planes at 22\%, 31\% and 46\% chord and $98 \%$ relative height.

Mach number distributions are depicted in figure 10. Different sections are represented on 
the same figure : a section at $98 \%$ of relative height, and 3three sections at respectively $22 \%$, $31 \%$ and $46 \%$ of the axial chord respectively. The normalized helicity $h$ is defined by:

$$
h=\frac{\underline{\operatorname{rot}}(\underline{V}) \cdot \underline{V}}{\|\underline{\operatorname{rot}}(\underline{V}) \cdot \underline{V}\|}
$$

Despite the similar numerical methods implied in the two calculations, and an ensemble average which aims at comparing these two different approaches equally, the development of the tip-leakage vortex differs. Indeed, on the-one hand, from the leading edge to section $22 \%$ chord, the same entropy field is visible for the two computations. The tip-leakage vortex rolls up and then extends azimuthally. On the other hand, from section $31 \%$ chord, two different behaviours are captured by the methods. In ZDES, the high entropy zone is concentrated on a thin line following the tip-leakage vortex. By contrast, the high entropy zone is wider in URANS. Besides, downstream section 31\%, and thus in section 46\%, the high entropy zone spreads all over the blade channel up to the adjacent blade. This impacts the boundary layer on the casing in the tip gap of the adjacent blade, and as a consequence, amplifies the contamination. The normalized helicity shows the rotating direction and the intensity for the vortices, especially the main tip-leakage vortex. Figure 10(b) and 10(e) indicate the main tip-leakage vortex development in red and the contra-rotative induced vortex near the shroud in blue. The comparison highlights the dissipation of the main tip-leakage vortex with the URANS method. Downstream section 31\%, the helicity decreases rapidly up to the levels of the main stream at section $46 \%$. On the contrary, in the ZDES computation, the helicity levels are more important for the main tip-leakage vortex and the induced vortex. Furthermore, the high levels are maintained further downstream and further azimuthally, up to section $46 \%$. Therefore, the main tip-leakage vortex remains coherent beyond section $31 \%$ chord. This points out a major difference in the capability of the two methods to capture the vortices, and reveals a major event occurring around sections $22 \%$ and $31 \%$ chord. The relative Mach number field is depicted in figures $10(\mathrm{c})$ and $10(\mathrm{f})$ and shows a shock at section $22 \%$ near the edge between the tip-gap and the suction side, and close to the casing. This shock position is captured by the two methods, albeit it is more intense in the ZDES case. The origin of the differences between the two methods is the behaviour of the tip-leakage flow crossing this shock. The shock is known to trigger high dissipation when a turbulent flow passes through it, even with LES. ${ }^{60}$ Nevertheless, the shock is weak. The gradients for the Mach number are not important. Besides, there is no sudden drop in the Mach number value after the shock neither a recirculation area. ${ }^{61}$ As a consequence, the difference between the two methods is triggered by the passage through a weak shock. 


\section{IV.A.2. Vortical structures}

The insight into the capability of the ZDES seen previously is verified in the vortical structures analysis below.

The iso-surfaces of Q criterion, ${ }^{62}$ coloured by the normalized helicity, ${ }^{63}$ along with a plane at $31 \% \mathrm{X} / \mathrm{C}$ filled with the entropy are presented in figures 11(a), 11(b), 11(c), 11(d) for the URANS computation and in 11(e), 11(f), 11(g), 11(h) for the ZDES. Four different times are represented in these snapshots: T/4 (figures 11(a),11(e)), 2T/4 (figures 11(b),11(f)), 3T/4 (figures 11(c),11(g)) and T (figures 11(d),11(h)). First of all, the richness in terms of vortical structures is the main difference between the two methods.

The URANS captures only the main vortices as long as they are stable enough. The main tip-leakage vortex and its contra-rotative induced vortex are visible with the two methods, in figure 11(a) and 11(e). Nevertheless, they extend further downstream in ZDES. This is due to their high unsteadiness from plane $31 \% \mathrm{X} / \mathrm{C}$ onward, which is dissipated by the URANS approach, and as a consequence, not captured.

The ZDES reveals multiple flow patterns similar to the ones suggested by Bindon ${ }^{3}$ on a turbine cascade. The tip clearance flow leaks through channels from the pressure to the suction side of the blade. The flow angle depends on the chordwise position. Secondary tip-leakage vortices, as the one pointed in figure 11(g) migrates from the trailing edge (TE) toward the leading edge (LE). Then, once close to the main tip-leakage vortex, their direction changes, they roll up around it due to its high rotational momentum and finally disrupt. The secondary tip-leakage vortex which is the closest to the main tip-leakage vortex has a specific behaviour: it does not migrate from the TE and the resulting secondary vortex, pointed in figure 11(f), rolls up from the same position as it can be seen in figures $11(\mathrm{e}), 11(\mathrm{f}), 11(\mathrm{~g})$ and $11(\mathrm{~h})$.

A tip-leakage vortex flutter phenomenon is visible in the present configuration, both in URANS and ZDES. The IGV wake and its tip vortex, visible in figure 6 , meet periodically the LE of R1 which leads to this flutter. This arrival is highlighted at section $31 \% \mathrm{X} / \mathrm{C}$ in figure 11(d). The interaction between the wake and the tip clearance flow, hence this flutter, was already experimentally emphasized by Mailach et al., ${ }^{8}$ albeit not with an incoming vortex from the stator as it is the case here. The velocity deficit of the main flow deflects the leakage flow direction as shown in figures $11(\mathrm{~b})$ and $11(\mathrm{f})$. As a consequence, the tip-leakage vortex moves away from the suction side of the blade with a period of $\mathrm{T}$ and the axial position of its disruption wanders around $31 \% \mathrm{X} / \mathrm{C}$.

It must be noticed that the tip-leakage vortex evolution along the chord is differentpredicted differently depending on the method used. This is illustrated by the entropy variation in four axial planes at position $22.3 \%, 31 \%, 46 \%$ and $91 \% \mathrm{X} / \mathrm{C}$, in figure 12 . Even if the tip-leakage vortex develops at the LE, the boundary layers from both the tip of the blade 


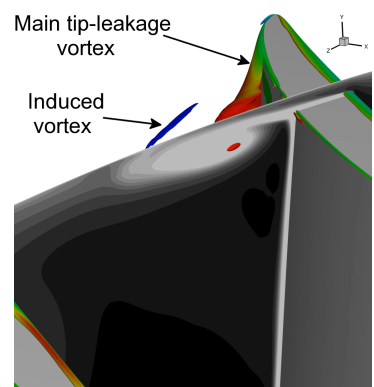

(a) $t=T / 4$

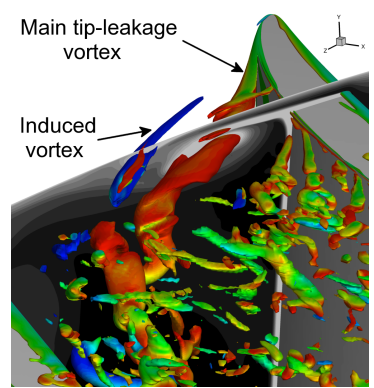

(e) $t=T / 4$

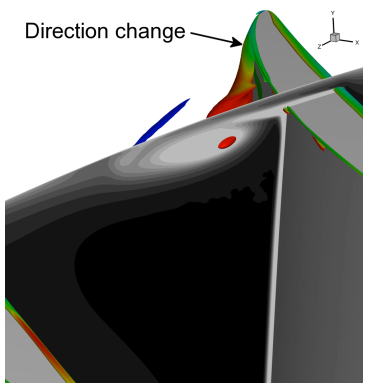

(b) $t=2 T / 4$

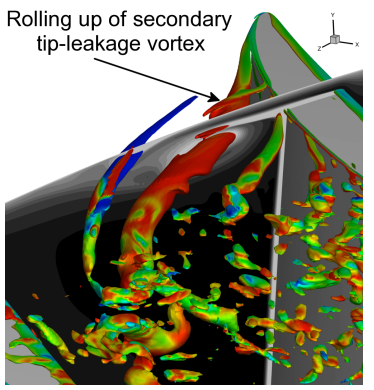

(f) $t=2 T / 4$

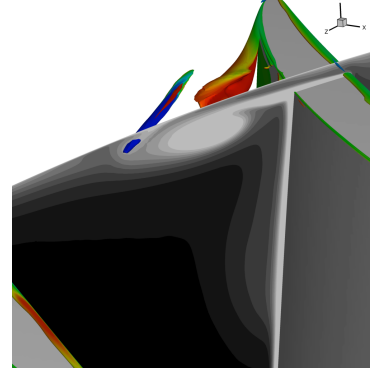

(c) $t=3 T / 4$

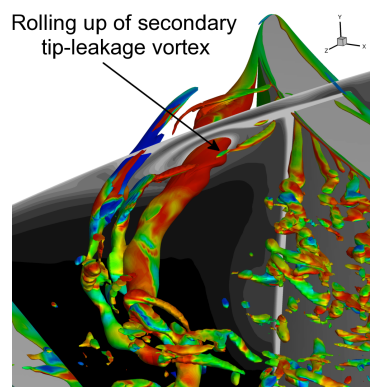

(g) $t=3 T / 4$

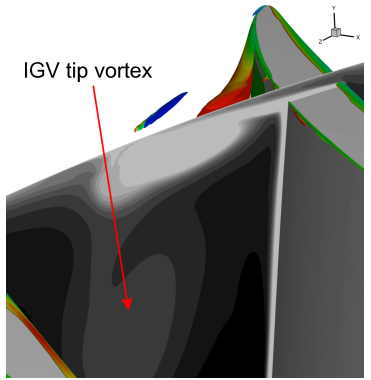

(d) $t=T$

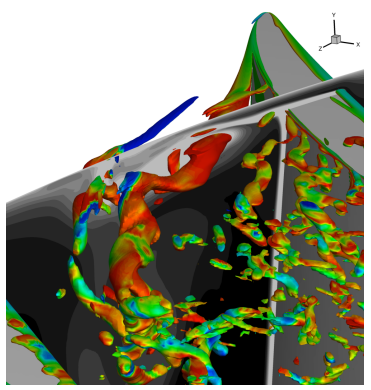

(h) $t=T$

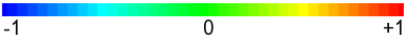

Normalized helicity

Figure 11. Snapshots of $\mathrm{Q}$ criterion iso-surface coloured by the normalized helicity and section $31 \% \mathrm{X} / \mathrm{C}$ filled with the entropy variation (top: URANS, bottom: ZDES).

and its suction side supply the tip-leakage vortex along the chord. The resulting tip-leakage vortices are generated at this shared edge between the blade suction side and the blade tip, this from the LE to the TE of the blade, figure 12(h). In figures 12(a) and 12(b), the tip-leakage vortex rolls up and its development is as advanced in URANS as in ZDES. IGV wake and tip vortex are visible on these two figures, around $25 \%$ of the azimuthal range from the pressure side. The IGV tip vortex is much larger than the IGV wake and induces a migration of high entropy flow from the casing boundary layer. These vortex and wake are also observed on figure 6 which is relative to inflow BC. From $31 \% \mathrm{X} / \mathrm{C}$, the topology differs between the two methods. The vortex coming from the IGV tip stretches periodically the tip-leakage vortex azimuthally and accelerates the casing boundary layer separation. This is clearly shown by figure $12(\mathrm{~d})$ which also shows that the IGV wake has not an important role in this stretching, contrary to the IGV vortex as the key element here is the velocity deficit which is more important within the IGV tip vortex. Moreover, another key element is the high entropy area which is representative of low momentum area. As the high entropy area of IGV tip vortex is larger than the area of IGV wake, the interaction between IGV vortex and tip-leakage vortex is higher than between IGV wake and tip-leakage vortex. The casing boundary layer separation occurs even when the IGV tip vortex does not meet the 


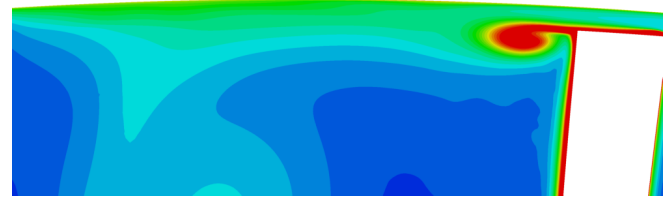

(a) $22.3 \% \mathrm{X} / \mathrm{C}$, URANS

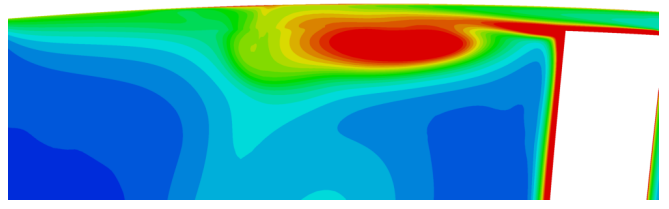

(c) $31 \% \mathrm{X} / \mathrm{C}$, URANS

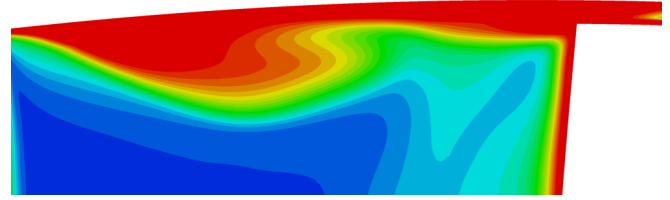

(e) $46 \% \mathrm{X} / \mathrm{C}$, URANS

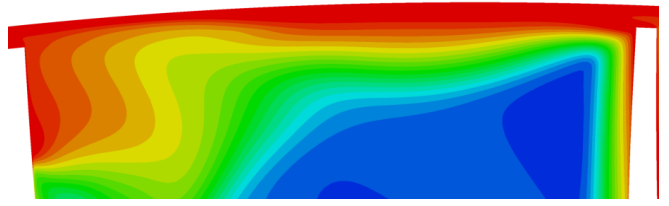

(g) $91 \% \mathrm{X} / \mathrm{C}$, URANS

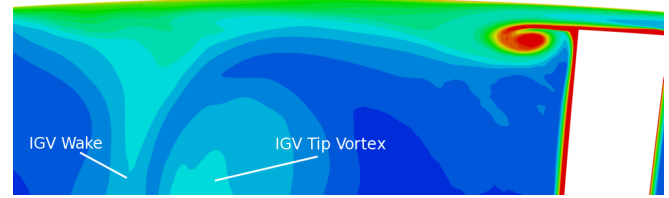

(b) $22.3 \% \mathrm{X} / \mathrm{C}$, ZDES

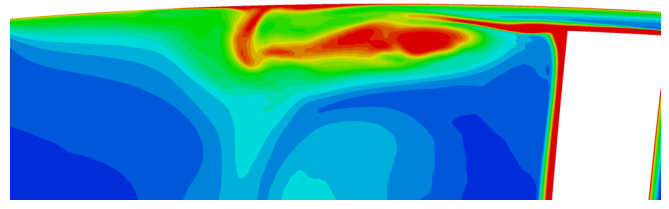

(d) $31 \% \mathrm{X} / \mathrm{C}$, ZDES

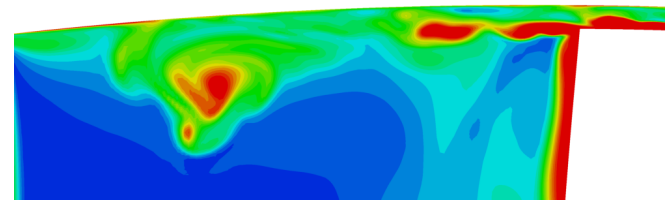

(f) $46 \% \mathrm{X} / \mathrm{C}$, ZDES

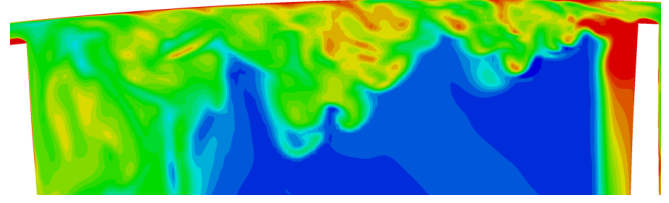

(h) $91 \% \mathrm{X} / \mathrm{C}, \mathrm{ZDES}$

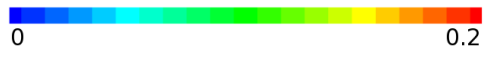

Entropy variation

Figure 12. Entropy variation for four different axial positions at $t=3 T / 4$ (left: URANS, right: ZDES).

tip-leakage vortex. In that case, this separation is only due to the interaction with the tip leakage vortex and the flow separates downstream of $31 \% \mathrm{X} / \mathrm{C}$. This is only observed with ZDES as URANS predicts different tip leakage vortex behaviors as discussed later. However, it separates downstream of $31 \% \mathrm{X} / \mathrm{C}$ when there is no influence of the IGV tip vortex. This boundary layer separation was already referenced on an axial compressor by Gourdain and Lebœuf ${ }^{64}$ to explain one of the origins of flow blockage near the casing. With the URANS method, the entropy levels are higher, continuous and azimuthally spread as it can be seen at plane $46 \% \mathrm{X} / \mathrm{C}$ in figure $12(\mathrm{e})$. Thereby, the tip-leakage vortex dissipates earlier with the URANS approach and contaminates the boundary layer to the adjacent blade near the TE, figure $12(\mathrm{~g})$. It should be noticed that the distinction between tip-leakage vortex and casing boundary layer separation cannot be observed with URANS because of the merge of high entropy areas. On the contrary, in ZDES, the entropy field is composed of scattered high entropy spots, in figures $12(\mathrm{~d}), 12(\mathrm{f})$ and $12(\mathrm{~h})$, corresponding to the continuity of the 
tip-leakage vortex and to multiple smaller vortices visible in figure $11(\mathrm{~g})$. At $91 \% \mathrm{X} / \mathrm{C}$, near the TE, the difference is even more pronounced than upstream. Indeed, at this position the main tip-leakage vortex has almost completely turned into smaller vortices with the ZDES approach.

\section{IV.B. Basic validation}

After the flow visualization of the previous section, which can be regarded as the level 0 of analysis giving keys to understand discrepancies between URANS and ZDES computations, this section deals with the first level of validation from Sagaut et al. ${ }^{65}$ which are summarized in table 3. The two first levels concern the effects of the choice of the method, either RANS, URANS or ZDES, on the performances and time-averaged radial profile of the compressor blade (cf. subsection IV.B.1) while the highest level investigated here deals with the onepoint spectral analysis (cf. subsection IV.B.3).

Table 3. Level of validation, from Sagaut \& Deck $^{65}$

\begin{tabular}{|c|c|}
\hline grade & level of validation \\
\hline 1 & integral forces (lift, drag and pitch) \\
2 & mean aerodynamic field (velocity or pressure profiles) \\
3 & second-order statistics (r.m.s. quantities) \\
4 & one-point spectral analysis (power spectral densities) \\
5 & two-point spectral analysis (correlation, coherence and phase spectra) \\
6 & high-order and time-frequency analysis (time-frequency, bicoherence spectra) \\
\hline
\end{tabular}

\section{IV.B.1. Overall performances and radial distribution}

Convergence of the computations is checked through stabilization of mean and root-meansquare static pressure of several numerical probes over a sliding temporal window containing 1000 iterations, that is to say, over one passage of the Inlet Guide Vane (IGV). The three computations on $\mathrm{R} 1$ are compared with mean experimental results deduced from two different kinds of probes. ${ }^{66}$ The unsteady probes and computation data are averaged in time and then in azimuth while the steady data from RANS and pneumatic probes are azimuthally averaged. The averages apply to 17T for ZDES and 18T for URANS, where $\mathrm{T}$ is the passage time period of the IGV with respect to R1.

Table 4 summarizes for the three computations on R1 the total pressure ratio and mass flow normalized with the pneumatic probes data. Globally, the overall performances of the first rotor are close to the experimental ones. The discrepancy is lower than $2 \%$ for the 
normalized mass flow and lower than $0.8 \%$ for the total pressure ratio. Despite the unsteady aspect of URANS and even the use of a rotating distortion, one can see that its prediction of performance values are close to the ones for RANS. Even if similar numerical methods and boundary conditions are used for all the computations of this study, RANS, URANS and ZDES, the global value results differ when considering the ZDES case. Indeed, the ZDES computation overestimates the experimental values for the mass flow like the other computations whilst it underestimates the pressure ratio. The global values show that the ZDES case is not absolutely in better agreement with the experimental measurements than the RANS or URANS cases. Indeed,In a compressor map, there is a hard link between total pressure ratio and mass flow. In the stable branch of a compressor map, a higher mass flow is linked to a smaller total pressure ratio as shown in figure 13(a) on which the "RANS - reference" computation is a RANS-SA computation with the same numerical parameters but with a fine RANS mesh (4.3 million points). As ZDES predicts the tip flow more accurately, the total pressure losses are better predicted and the operating point obtained with ZDES is closer to experimental nominal speed line as shown by the dotted line. Unfortunately, the operating point is not strictly equal to experimental nominal point. The mass flow is slightly higher leading to a smaller total pressure ratio. On the contrary, as RANS and URANS predict differently the tip flow, the nominal speed line is a little farther from the experimental one. Thus, even if the mass flow is slightly higher, the total pressure ratio is also higher. The comparison between RANS, URANS and ZDES shows that the global values for the ZDES are not simply shifted from the RANS values toward the experimental ones. This is more complex and denotes an important change in the flow topology.

Table 4. Mass flow and total pressure ratio for the different computations on R1, normalized with pneumatic probes data.

\begin{tabular}{|c|c|c|}
\hline Case & Normalized mass flow & $\begin{array}{c}\text { Normalized R1 total pressure } \\
\text { ratio }\end{array}$ \\
\hline Pneumatic probes & 1.000 & 1.000 \\
\hline RANS & 1.020 & 1.006 \\
\hline URANS & 1.019 & 1.005 \\
\hline ZDES & 1.014 & 0.992 \\
\hline
\end{tabular}

The radial distribution of total pressure at section $26 \mathrm{~A}$ is plotted in figure $13(\mathrm{~b})$. The averaged unsteady probes symbol comprises the interval with the measure uncertainties. First of all, even if the two experimental data are very close at mid span, the gap widens and reaches up to $1 \%$ in turbulent regions, such as the tip-leakage flow at $80 \%$ relative height. These zones reveal the highest discrepancies between the numerical methods too. 


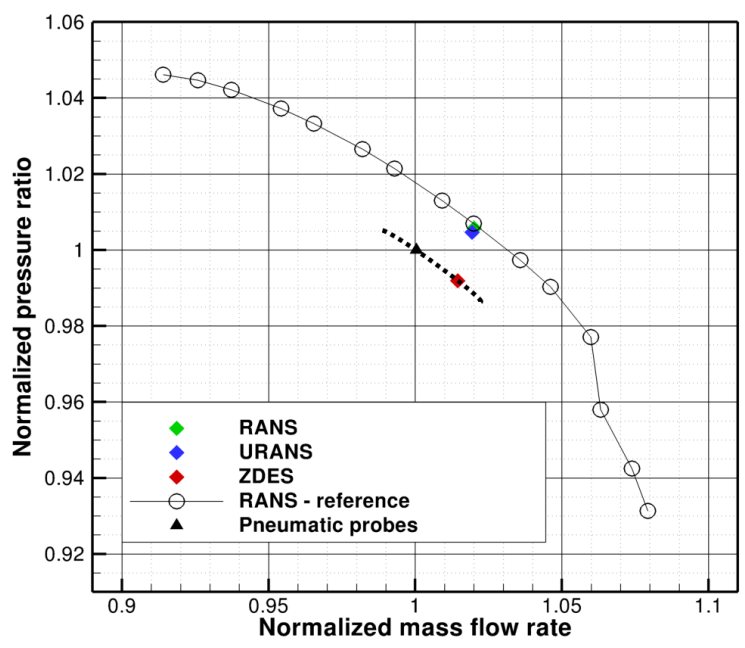

(a) Compressor map

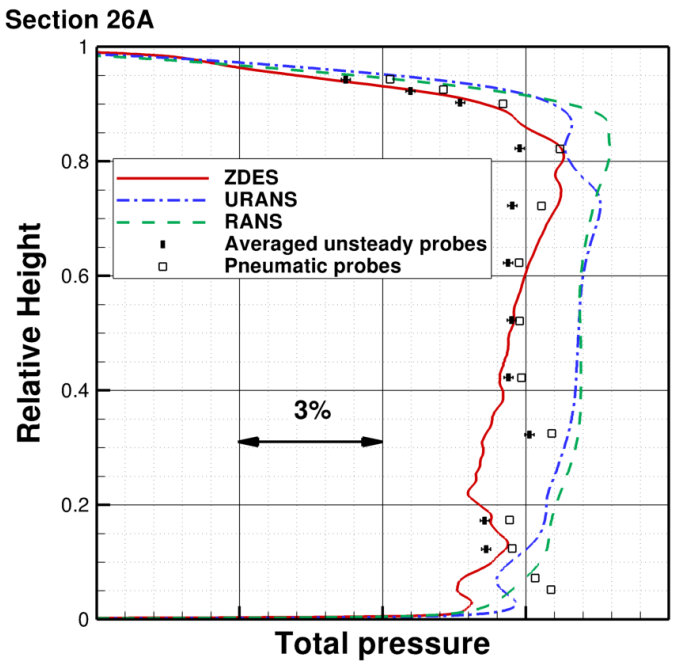

(b) Azimuth and time averaged total pressure at section $26 \mathrm{~A}$

Figure 13. 1D and 2D performances at section 26A.

The pressure gradient induced by the secondary flows near casing, from $100 \%$ to $85 \%$ relative height, is better captured in ZDES than in URANS and RANS which under-estimate it. However, URANS succeeds in capturing the effects on total pressure at $80 \%$, like the ZDES method. Both methods are close to the pneumatic probes value at $80 \%$, albeit still $1 \%$ higher than the averaged unsteady probes. This radial position, along with the one at $10 \%$ which corresponds to a hub corner effect, is the only one where URANS differs clearly from RANS and gets closer to the ZDES results, indeed, the twoas RANS methodsand URANS are similar at mid-span.

It must be noticed that ZDES brings significant improvement over methods based on averaged Navier-Stokes equations for the tip-leakage flow and even at mid span. Nevertheless, at $30 \%$ relative height, the computations provide total pressure values which do not match the probes measurements, with an under-estimation of $1 \%$ for ZDES and an over estimation of the same order of magnitude for the RANS and URANS methods, depending on the considered probe. A hypothesis for this pressure increase could be that the recirculation from the axial gap upstream from R1, which can be seen in figure 2, modifies the pressure distribution locally at $30 \%$ relative height in section $26 \mathrm{~A}$. This phenomenon, which is still to be determined, could not be seen in the configuration set in this paper since no hub recirculation is modelled compared to the configuration studied by Marty et al. ${ }^{67}$ 


\section{IV.B.2. Laser-Doppler-Anemometry comparison}

It is possible to track the development of the tip clearance flow between two blades of the R1 by the means of the Laser Doppler Anemometry (LDA) measurements carried out on the CREATE compressor. Two dimensional LDA measures the axial and circumferential velocity components at $91 \% \mathrm{X} / \mathrm{C}$ and $90 \%$ relative height along the 11.5 degrees of the azimuthal range. The normalized time averaged values are presented in figure 14 for the axial velocity and in figure 15 for the circumferential velocity. They are compared to data from the computations: URANS and ZDES. The velocities are normalized by the maximum velocity from the LDA measurement at this relative height and chord position. Since the visualization are represented in the rotor frame of reference, the relative azimuthal position is unknown. Thereby, the relative position between the computations and the experimental values is based on the gradients.

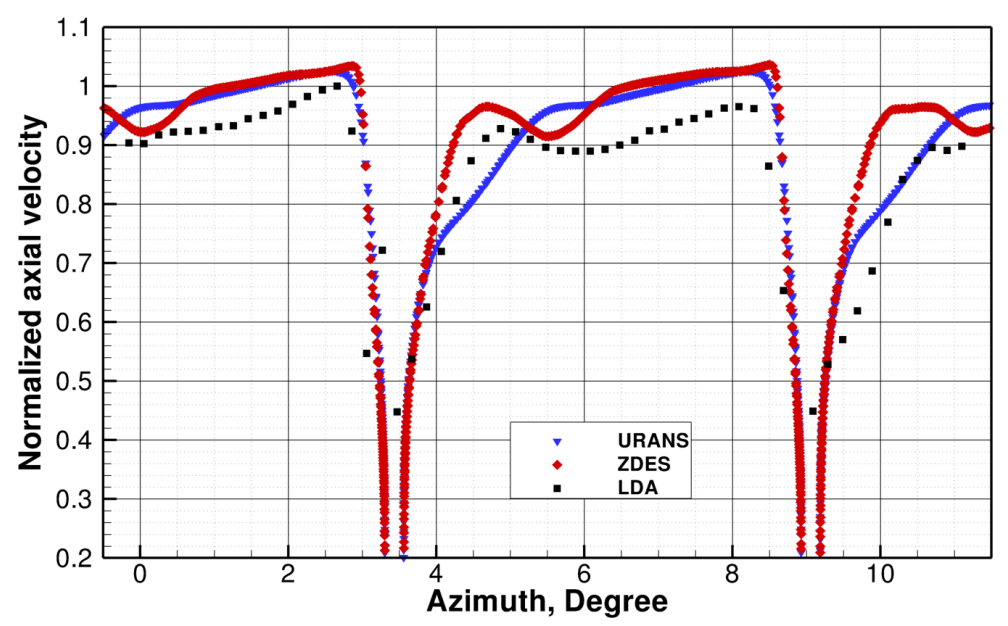

Figure 14. Averaged normalized axial velocity at $91 \% \mathrm{X} / \mathrm{C}$ and $90 \%$ relative height.

The vortex core is identified by its local minimum of axial velocity. The LDA measurements are not periodical with respect to the IGV blade count. This can be explained by the non periodic configuration of the test rig. This can be explained by the periodicity of the test rig which is not exactly $2 \pi / 32$-periodic but $2 \pi / 4$-periodic due to structural struts located upstream of the IGV. As these struts are far from the first rotor, they are not included in the computational domain.

Near the trailing edge of the blade, at section $91 \% \mathrm{X} / \mathrm{C}$, and further from the casing, at $90 \%$ of relative height, the main tip leakage vortex is not observed in URANS computation as it is totally dissipated. By contrast, there is an axial velocity deficit at azimuth 5.5 in ZDES. This position is nonetheless not the one which corresponds to the tip-leakage vortex in the LDA measurements, which is azimuth 6. Besides, its widening is more important in the experiments. By adding the overestimation of the axial velocity seen throughout the 


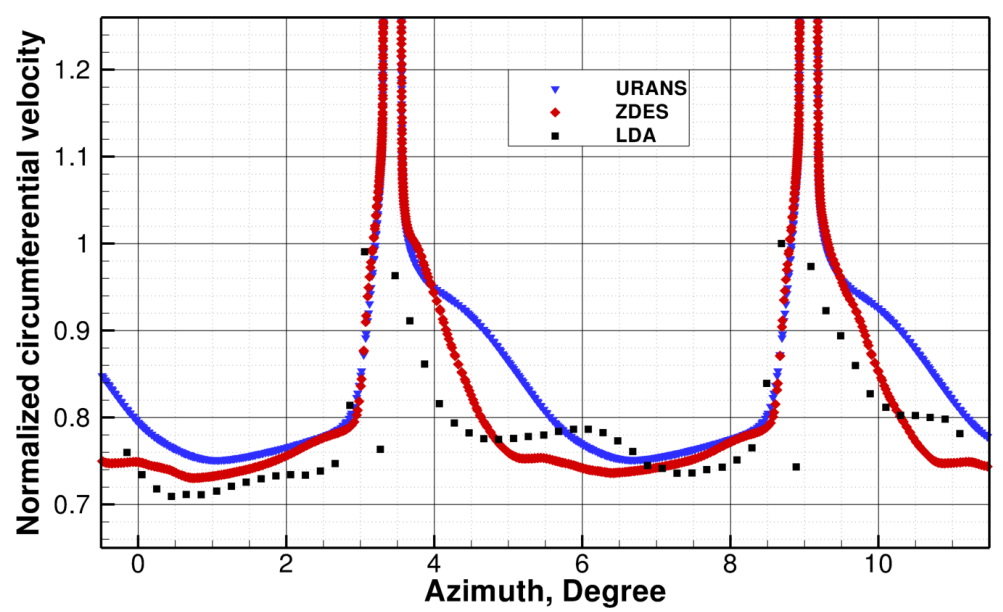

Figure 15. Averaged normalized circumferential velocity at $91 \% \mathrm{X} / \mathrm{C}$ and $90 \%$ relative height.

passage, this strengthens the hypothesis of a slight discrepancy concerning operating point between the experimental case and the computations. It is reminded that the normalized massflow is overestimated with ZDES by $1.4 \%$. The analysis of the circumferential velocity in figure 15 emphasizes that the ZDES captures more accurately the tip-leakage flow more accurately. Indeed, the levels are in better agreement, and the step at azimuth 6 is captured, albeit it is less pronounced than what it is experimentally. This step is not captured by the URANS approach. Nevertheless, one has to underscoreit should be noticed that between azimuth 6 and 8 the levels are similarly captured by all the methods/ Despite this issue concerning the operating point definition, the ZDES conserves the tip-leakage vortex beyond the shock contrary to the URANS approach that rapidly dissipates it.

Now, the analysis focuses on the unsteadiness within the flow. Therefore, a statistic of second order is studied. It corresponds to the level 3 in the levels of validation. In order to follow the tip-leakage flow development, and to compare to what was previously done, the same positions are used for the azimuthal distributions presented here. The standard deviation $^{68}$ of the velocities is computed using the same time range as the averages presented previously.

Figures 16 and 17 depict the standard deviation of axial and circumferential velocities respectively, near the trailing edge of the blade, at $91 \% \mathrm{X} / \mathrm{C}$ and $90 \%$ of relative height. The value is higher near the blade around azimuth 4 and decreases as the azimuth increases up to the other blade, for both velocities. In figure 16, the azimuths 4-6 denote the position of the rim of the main tip-leakage vortex. Contrary to the URANS approach, the values for the ZDES are in good agreement with the measurements. On the one hand, the intensity and position of this vortex is correctly captured by the ZDES method. On the other hand, 


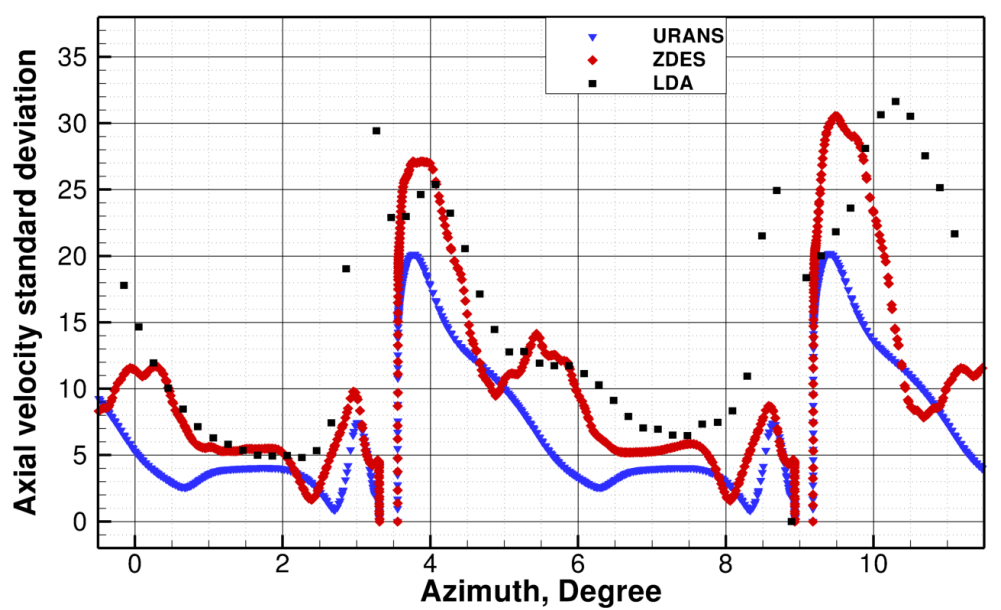

Figure 16. Axial velocity standard deviation at $91 \% \mathrm{X} / \mathrm{C}$ and $90 \%$ relative height.

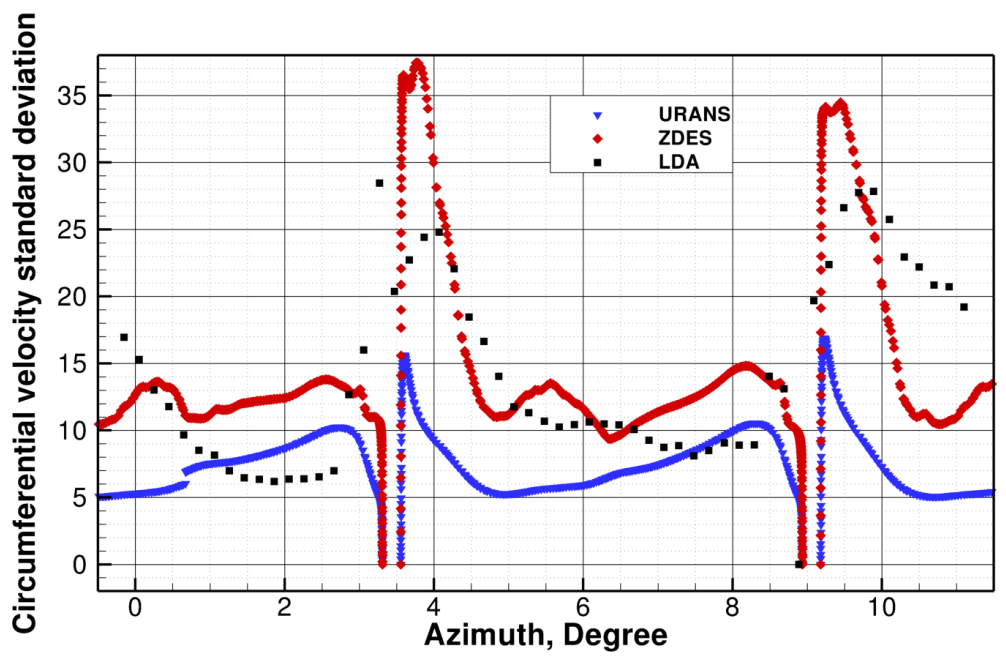

Figure 17. Circumferential velocity standard deviation at $91 \% \mathrm{X} / \mathrm{C}$ and $90 \%$ relative height.

the URANS does not capture it at all. Moreover, the levels are lower in URANS with an almost constant 5\% discrepancy with the LDA measurements along the azimuth. Figure 17 shows similar results for the circumferential velocity standard deviation at the same position. The ZDES captures unsteadiness levels that suit better the azimuthal distribution observed experimentally than the URANS computation. This confirms that the URANS method underestimates the unsteadiness in both directions downstream the shock position while ZDES tends to conserve the tip-leakage vortex and therefore the unsteadiness of this vortex.

\section{IV.B.3. Spectral analysis of pressure fluctuations}

In the following, all spectral analysis are based on the same method. The Power Spectral Density (PSD) is based on the Welch ${ }^{69}$ method using an overlap of $50 \%$ and ten Hann 
windows with a linear mean for each. The frequency resolution (FR) is $2000 \mathrm{~Hz}$ for the data set arising from a temporal range of $17 \mathrm{~T}$ for the ZDES and $18 \mathrm{~T}$ for the URANS. An estimation of the cut-off frequency gives $3.210^{5} \mathrm{~Hz}$. It is based on the cubic root of the cell volume and a characteristic velocity for the turbulent structures defined as $\sqrt{u^{\prime 2}+{v^{\prime}}^{2}+w^{\prime 2}}$, with $\mathrm{u}, \mathrm{v}$ and $\mathrm{w}$ respectively the maximum of the fluctuating velocity in the $\mathrm{X}, \mathrm{Y}$ or $\mathrm{Z}$ directions. It is important to keep in mind that the effective cut-off may be at a lower frequency due to the numerous effects that influence it, such as the mesh refinement and the numerical schemes. The PSD describes how the root mean squared value of the static pressure is distributed in the frequency spectrum and represents the flow energy. On all plots, for a better understanding, another parameter is displayed : the reduced frequency. It consists in the signal frequency normalized by the IGV blade passing frequency (BPF).

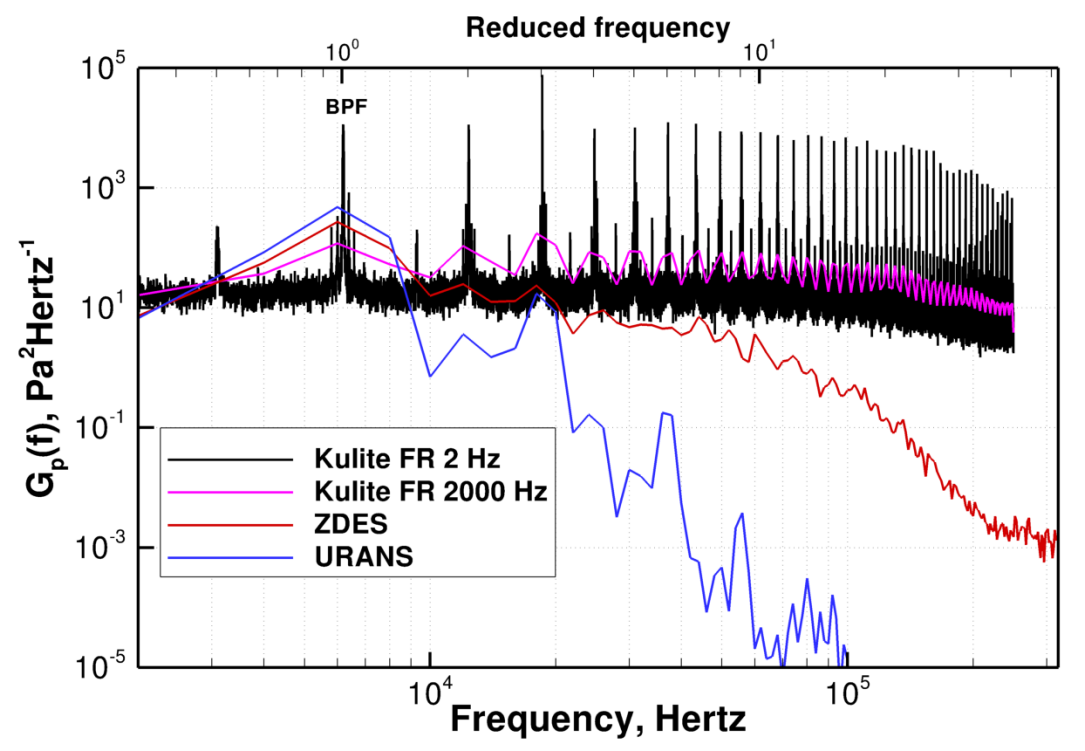

Figure 18. Power spectral density (PSD) of static pressure for a probe at the casing in plane 26A.

The power spectral density $G_{p}(f)$ of the static pressure is plotted as a function of the frequency in figure 18 for the probes at the casing. First of all, the frequency resolution is $2000 \mathrm{~Hz}$ for the numerical data set arising from a temporal range of $17 \mathrm{~T}$ for the ZDES computation and $18 \mathrm{~T}$ for the URANS one. This resolution results from the aforementioned minimum number of Hann windows required for the Welch method. By contrast, the resolution for the unsteady probes is of $2 \mathrm{~Hz}$. This is a limiting factor for the comparison of the numerical probes with the experimental ones, especially for the low frequency phenomena. The reason is that the lowest captured frequency is the frequency resolution. Thereby, the phenomena with a characteristic frequency inferior to the frequency resolution of a PSD are not captured. Another effect of the frequency resolution is the level of energy visible in the graphs. Indeed, a small frequency resolution leads to a more accurate capture of the 
frequency of a phenomenon, denoted by a thin and high peak of energy on the graph. On the contrary, the same phenomenon captured with a higher value for the frequency resolution will result in a wider and shorter peak due to the energy distribution on a wider range of frequency. This effect on the energy level is the reason why the PSD for the unsteady probe are displayed with two frequency resolutions: $2 \mathrm{~Hz}$, which is the best available resolution regarding the length of the experimental data set, and $2000 \mathrm{~Hz}$, which is the same frequency resolution as the one for the numerical probes from the computations.

The energy level of the BPF is correctly captured by the computations if the corresponding levels are compared with the same frequency resolution. However, from the second harmonic and beyond, the energy levels for the URANS approach drop by one order of magnitude compared to the ZDES levels. The third harmonic, which is the one with the highest energy level, is captured by the two computations with a level similar to the second harmonic. Although its energy level is superior to the BPF level experimentally, it is inferior by two orders of magnitude for the computations. This could originate from rotor-stator interactions such as the potential effects from the first stator (S1). The S1 has 96 blades which coincides with 3 IGV BPF which comprises 32 blades. This effect is not taken into account numerically since the S1 is not computed in this investigation. As a result, a part of the discrepancy between the experiment and the computations located from the third harmonic of the BPF could be explained by this potential effect. Then, from 4 times the BPF, the discrepancy between the URANS and the ZDES methods increases and the URANS energy value drops off rapidly. Instead of having its energy dropped off at the same rate as the URANS method, the ZDES computation keeps energy levels close to the ones for the experimental probes up to the $10^{\text {th }}$ harmonic. Nevertheless, there is an important decrease of the energy levels beyond this harmonic. At the $20^{\text {th }}$ harmonic, the experimental PSD has a slope inflection.

Moreover, a low frequency phenomenon is visible for the experimental probe PSD only with the smallest frequency resolution. This frequency is probably related to the machine periodicity and to rotor-stator interactions, and can not be captured by the computations. This phenomenon corresponds to $1 / 2 \mathrm{BPF}$, and is neither captured by the unsteady probe PSD with $2000 \mathrm{~Hz}$ of frequency resolution nor by the computations. For instance, the interaction mode $2 \mathrm{BPF}_{\mathrm{R} 1}-\mathrm{BPF}_{\mathrm{S} 1}$ can correspond to the $1 / 2 \mathrm{BPF}$ of the IGV.

\section{IV.C. Spectral analysis along the tip-leakage vortex}

A spectral analysis is carried out so as to better understand the differences between the two methods. The Power Spectral Density (PSD) function of the static pressure is plotted for four probes. They are located at different axial positions along the main tip-leakage vortex core as presented in figure 19 with the instantaneous numerical Schlieren at $98 \%$ relative 
height and $\mathrm{t}=3 \mathrm{~T} / 4$. The probes 1 , in red, and 2, in blue, are located at $11 \%$ and $22.5 \%$ $\mathrm{X} / \mathrm{C}$. The probes 3 , in green, and 4 , in orange, are located at $33.8 \%$ and $45.7 \% \mathrm{X} / \mathrm{C}$. This means that probes 1 and 2 are upstream the tip-leakage vortex disruption contrary to probes 3 and 4.

The PSD functions are plotted for probes 1 and 2 in figure 20(a) and for probes 3 and 4, in figure 20(b). The normalized PSD, defined by $\frac{f \cdot G_{p}(f)}{\sigma^{2}}$ with $\sigma$ in equation (7), shows the contribution to the total energy of the different frequencies. They are plotted for probes 1 and 2 in figure 20(c) and for probes 3 and 4, in figure 20(d).

$$
\sigma^{2}=\int_{0}^{\infty} G_{p}(f) d f=\int_{-\infty}^{\infty} f \cdot G_{p}(f) d(\log (f))
$$

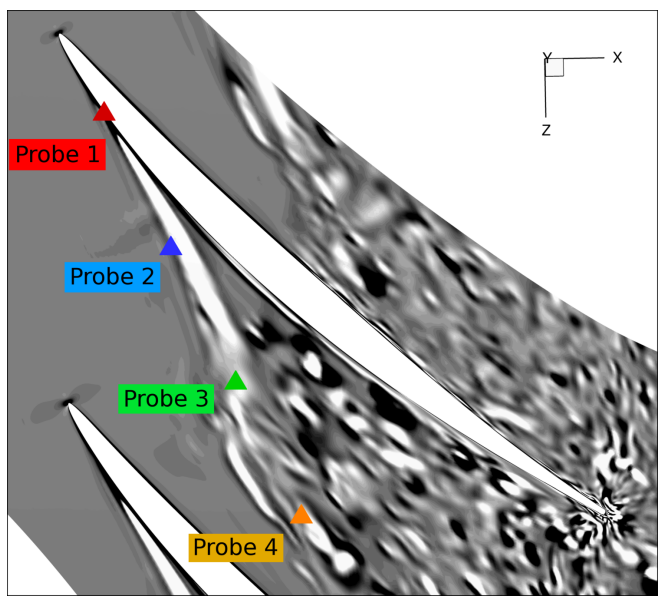

Figure 19. Probes position. ZDES. Instantaneous Schlieren at $98 \%$ relative height and $\mathrm{t}=3 \mathrm{~T} / 4$.

Up to section $31 \% \mathrm{X} / \mathrm{C}$, the energy level increases for every frequency, low, medium and high, and, above all, for both URANS and ZDES, figure 20(a). This characterizes a similar evolution of the tip-leakage flow. In addition, the magnitudes for probe 1 are close until $10^{5}$ $\mathrm{Hz}$, except for one peak at $38000 \mathrm{~Hz}$; then, they diverge. The frequency from which the two methods differ lowers as the probe is downstream. Indeed, for probe 2, it would be around $56000 \mathrm{~Hz}$.

From probe 3 onward, figure 20(b), the difference in magnitude is important. At probe 3 , the two methods match only at the low frequencies 6000 and $8000 \mathrm{~Hz}$. And finally, at probe 4, the whole spectrum is lower for URANS. Nevertheless, it must be noticed that the $6000 \mathrm{~Hz}$ frequency corresponds to the IGV passage frequency $(6156 \mathrm{~Hz})$ regarding the PSD resolution (FR). Its harmonics are captured by both methods, although the magnitudes differ. This is clearly seen with the reduced frequency which corresponds to the flow frequency divided by this IGV passage frequency. These magnitude discrepancies stem from a change in the 


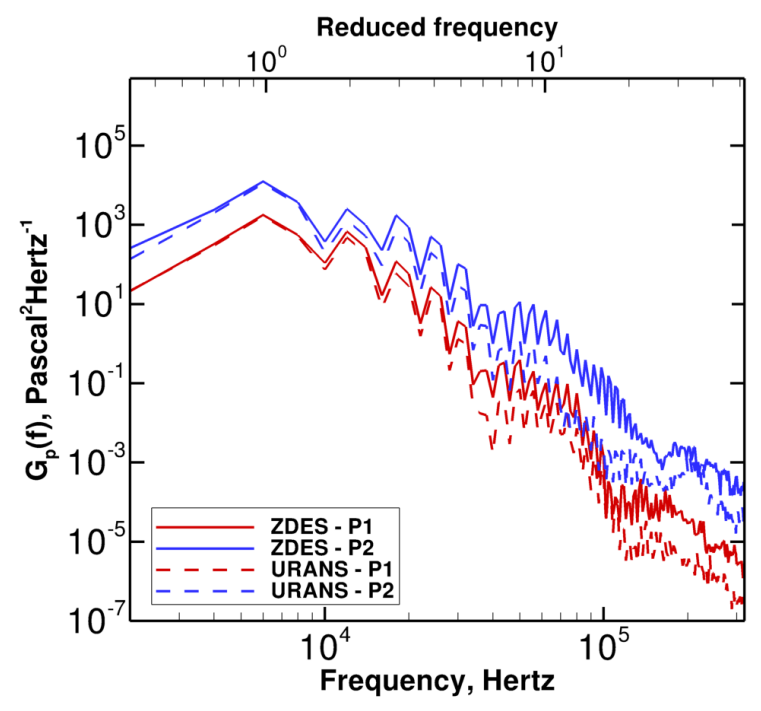

(a) Probes 1 and 2, PSD

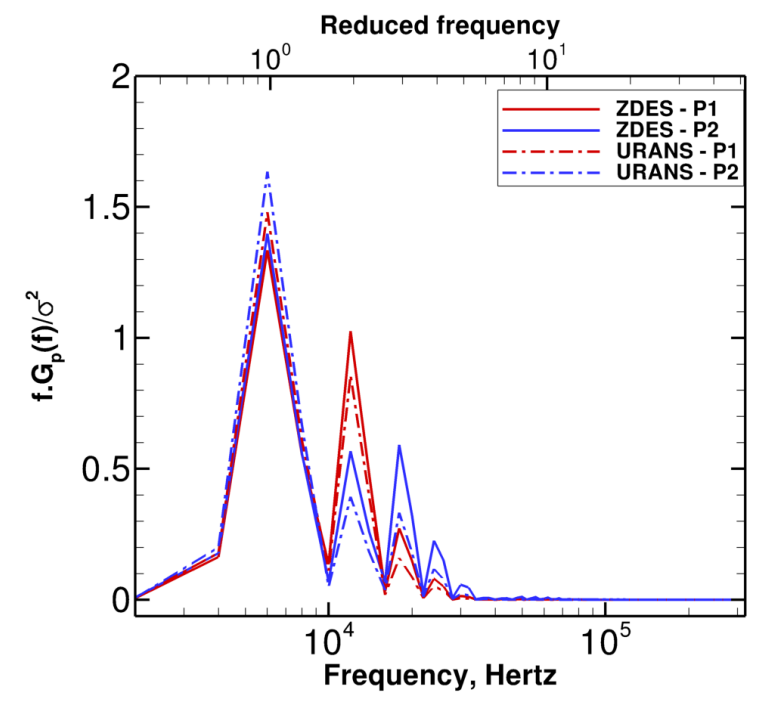

(c) Probes 1 and 2, normalized PSD

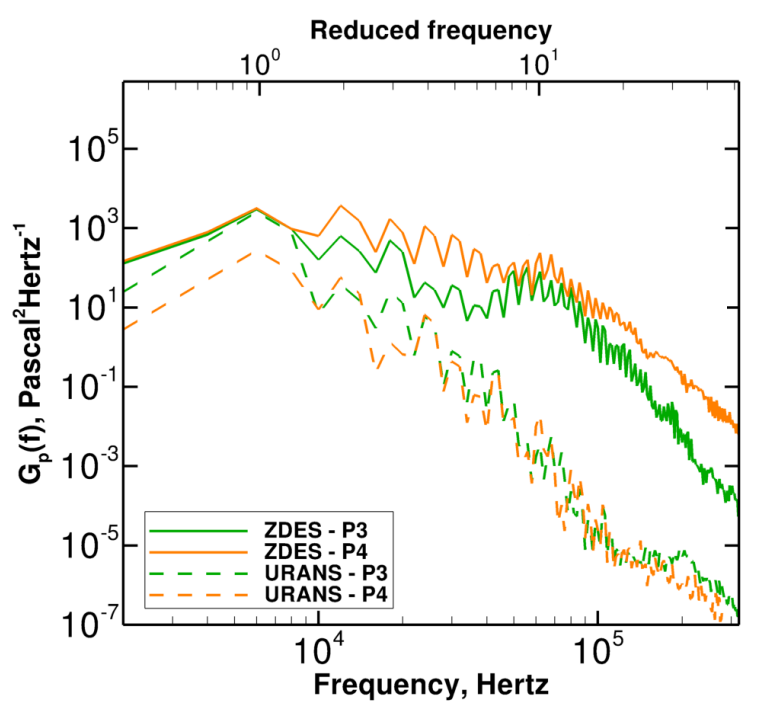

(b) Probes 3 and 4, PSD

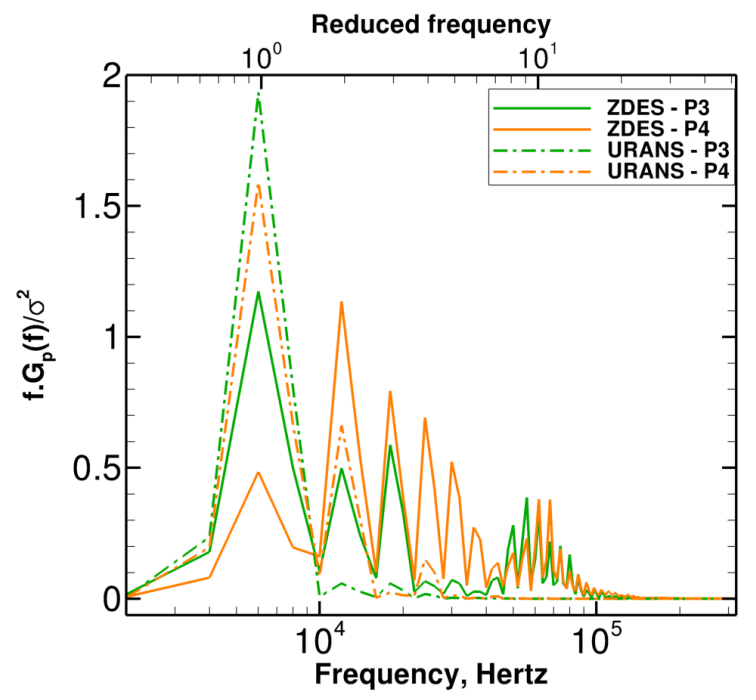

(d) Probes 3 and 4, normalized PSD

Figure 20. Power spectral density (PSD) of static pressure for probes along the tip-leakage vortex.

slope. Although the slope for probes 3 and 4 is similar to the one for probes 1 and 2 for the URANS method, it is distinctly divided into two zones for the ZDES from probe 3 and even more for probe 4. The inflection point is then located around $60000 \mathrm{~Hz}$ or $10 \mathrm{BPF}$.

The normalized PSD confirm the aforementioned differences. Figure 20(c) shows a similar behaviour for URANS and ZDES while analysing spectra from probes 1 and 2. Nevertheless, the energy contribution of the low frequencies to the whole energy is more important in URANS. This is directly linked to the lack of contribution of the highest frequencies above $30000 \mathrm{~Hz}$ in the URANS case, as highlighted in figures 20(c) and 20(d). The BPF second harmonic has its contribution halved from probe 1 to probe 2 , and higher harmonics appear 
to have more and more contribution to the whole energy. As high frequency phenomena do not have a significant contribution at this development stage of the vortex, the spectral signatures are close between URANS and ZDES.

From the vortex disruption at $31 \% \mathrm{X} / \mathrm{C}$, the spectral signature of the two methods differs regarding the energy contribution. Figure 20(d) indicates that after the vortex disruption, the energy contribution is focused on the first BPF harmonic in URANS. By contrast, for the ZDES computation, the second and third harmonics have a significant contribution. Moreover, a privileged frequency range of BPF harmonics, around $75000 \mathrm{~Hz}$, is only visible with the ZDES method. This frequency range is then correlated to the arrival of the IGV tip vortex and its important contribution to the whole energy is only triggered after the vortex disruption. However, its energy level is important even upstream section $31 \% \mathrm{X} / \mathrm{C}$. Indeed, it is visible around $75000 \mathrm{~Hz}$ in figure 20(a) for both methods and in figure 20(b) only for the ZDES method. Thereby the URANS method dissipates this phenomenon after the shock position contrary to the ZDES method. Besides, its frequency range corresponds to the inflection point for the slopes highlighted in figure 20(b), hence its link to the turbulenceturbulence interaction. Therefore, the inception of the effect of the turbulence-turbulence interactions on the total energy of the flow originates from the light shock located at section $31 \% \mathrm{X} / \mathrm{C}$.

The evolution of the spectra along the tip-leakage vortex corroborates the topology difference between the URANS and ZDES methods. On the-one hand, it is noteworthy to see the energy transfer from the low frequencies to the highest for the ZDES computation. As the main tip-leakage vortex evolves, the ZDES spectrum is broad banded, that is to say, the smallest turbulent structures develop. On the other hand, this behaviour is not present in URANS. In other words, the energy distribution in URANS is focused on low frequencies only and as vortices disrupt, the energy is not brought to smaller vortices.

This energy transfer explains the discrepancy between the two methods to simulate small turbulent structures and to accurately predict the evolution of the tip-leakage vortex.

\section{Conclusion}

The ability of three different numerical methods (namely RANS, URANS and ZDES) to simulate the tip clearance flow in an axial high pressure compressor has been assessed. Their capability to capture the physics of the tip-clearance flow in axial compressors has been tested on the same grid based on ZDES requirements, i.e. a LES resolution mesh except on the wall. The capacity of all methods to capture tip-leakage flow is assessed by comparison to experimental data, especially LDA measurements in the vicinity of the blade tip and power spectral densities of Kulite probes at casing. 
It has been shown that the RANS approach has clear limitations which prevent it from modelling the mean flow of unsteady phenomena. This method overestimates the global performances and is unable to capture the total pressure gradient near the casing. URANS improves the capability of RANS in high unsteadiness zones, such as the tip-leakage flow, but does not change its global simulation capacity as predicted performances are very close to RANS results. This is due to the intrinsic formulation of the methods both based on averaged Navier-Stokes equations.Moreover, this method captures only tip leakage and induced vortices and dissipates the tip leakage vortex across the weak shock. Thus the URANS method underestimates the velocity and pressure fluctuations and captures only the first three harmonics of BPF.

The ZDES method supplies considerable improvements over the ones based only on averaged Navier-Stokes equations, even for integral values. Moreover, the ZDES approach is able to reveal more complex phenomena than the other tested methods. Indeed, different flow patterns of the tip-leakage vortices were highlighted thanks to this method. The tip leakage vortex and the contra-rotative induced one are captured as well as numerous secondary vortices. Due to their interaction with the tip leakage vortex, secondary vortices roll-up around it. This leads to the generation of smaller vortices. Furthermore, this study improved the understanding of the interaction between the tip-leakage flow and the stator wake, the latter being made up of the blade wake itself along with a tip vortex and a hub vortex. This interaction leads to the tip leakage vortex flutter. These differences in tip leakage flow prediction explain the improvement of the prediction of the pressure and velocity fluctuations. The first ten harmonics are well captured by ZDES.

To benefit from all of these advantages, higher computing resources are necessary. Nonetheless, the ZDES approach enables to focus on the areas of interest and solves them with a LES resolution. Thus, the computing power can be better allocated than with conventional LES. It should be noticed that, as the same mesh and numerical parameters are used for URANS and ZDES methods, the CPU cost per iteration is the same in the present study. Nevertheless, the computational cost of ZDES method is significantly higher than URANS simulation based on URANS requirements because of the cell number of the mesh adapted to ZDES which is twenty times higher than the URANS one. This study also shows the importance of having high-quality experimental databases to assess advanced turbulence simulation methodologies.

Future work will concern further analysis of these methods at design point and their evaluation near surge so as to better understand its consequences on the tip-leakage flow. 


\section{Acknowledgments}

The authors wish to thank the C.I.R.T. members (LMFA, SNECMA, TURBOMECA, EDF and ONERA) who support this thesis work. The authors thank gratefully J. Riou (SNECMA) for his useful discussions during this study and X. Ottavy (LMFA) for providing the experimental data. The current publication is dedicated to F. Leboeuf.

\section{References}

${ }^{1}$ Herzig, H., Hansen, A., and Costello, G., "A visualization study of secondary flows in cascades," Tech. rep., Report 1163-National Advisory Committee for Aeronautics, 1954.

${ }^{2}$ Storer, J. and Cumpsty, N., "An Approximate Analysis And Prediction Method For Tip Clearance Loss In Axial Compressors," 38th International Gas Turbine And Aeroengine Congress and Exposition, ASME, Cincinnati, Ohio, No. 93-GT-140, May, 24-27 1993, pp. 648-656.

${ }^{3}$ Bindon, J., "The Measurement and Formation of Tip Clearance Loss," Journal of Turbomachinery, Vol. 111, 1989, pp. 257-263. doi: 10.1115/1.3262264.

${ }^{4}$ Kang, S. and Hirsch, C., "Experimental study on the three dimensional flow within a compressor cascade with tip clearance: Part I - Velocity and pressure fields," ASME, Vol. 92-GT-215, 1992, pp. 1-8.

${ }^{5}$ Kang, S. and Hirsch, C., "Experimental study on the three dimensional flow within a compressor cascade with tip clearance: Part II - The tip leakage vortex," ASME, Vol. 92-GT-432, 1992, pp. 1-7.

${ }^{6}$ Rains, D., Tip Clearance Flows In Axial Compressors and Pumps, Ph.D. thesis, California Institute of Technology, 1954.

${ }^{7}$ Suder, K. and Celestina, M., "Experimental and Computational Investigation of the Tip Clearance Flow in a Transonic Axial Compressor Rotor," J. Turbomach., Vol. 118, 1996, pp. 218-229. doi: $10.1115 / 1.2836629$.

${ }^{8}$ Mailach, R., Lehmann, I., and Vogeler, K., "Periodical unsteady flow within a rotor blade row of an axial compressor-part II : wake-tip clearance vortex interaction," Journal of turbomachinery ASME, Vol. 130, 2008, pp. 1-10. doi: 10.1115/1.2812330.

${ }^{9}$ Riou, J., "Tip-leakage-flow study using hybrid RANS/LES methods," 46th Symposium for Applied Aerodynamics, Orléans, France, 3AF, Orleans, Mar. 2011, pp. 1-10.

${ }^{10}$ Boudet, J., Caro, J., and Jacob, M., "Large-eddy simulation of a low-speed tip-clearance flow," 9th European Conference on Turbomachinery Fluid Dynamics and Thermodynamics, edited by M. Sen, G. Bois, M. Manna, and T. Arts, March 2011, pp. 147-158.

${ }^{11}$ Spalart, P., "Strategies for turbulence modelling and simulations," International journal for heat and fluid flow, Vol. 21, 2000, pp. 252-263. doi: 10.1016/S0142-727X(00)00007-2.

${ }^{12}$ Spalart, P., Jou, W., Strelets, M., and Allmaras, S., "Comments on the feasibility of LES for wings, and on a hybrid RANS/LES approach," Advances in DNS/LES, edited by L. S. C Liu, Z Liu, 1997, p. 13747.

${ }^{13}$ Spalart, P., Deck, S., Shur, M., Squires, K., Strelets, K., and Travin, A., "A new version of detachededdy simulation, resistant to ambiguous grid densities," Theoretical And Computational Fluid Dynamics, Vol. 20, 2006, pp. 181-195. doi: 10.1007/s00162-006-0015-0.

${ }^{14}$ Deck, S., "Zonal-Detached-Eddy Simulation of the Flow Around a High-Lift Conguration," $A I A A$ Journal, Vol. 43, 2005, pp. 2372-2384. doi: 10.2514/1.16810. 
${ }^{15}$ Deck, S., "Recent Improvements in the Zonal Detached Eddy Simulation (ZDES) Formulation." Theoretical and Computational Fluid Dynamics, Vol. 26, 2012, pp. 523-550. doi: 10.1007/s00162-011-0240-z.

${ }^{16}$ Brunet, V. and Deck, S., "Zonal-Detached Eddy Simulation of transonic buffet on a civil aircraft type configuration," 38th Fluid Dynamics Conference and Exhibit, AIAA, Seattle,Washington, 2008, pp. 1-12.

${ }^{17}$ Gand, F., "Zonal Detached Eddy Simulation of a Civil Aircraft with a Deflected Spoiler," AIAA Journal, Vol. 51, No. 3, 2012, pp. 697-706. doi: 10.2514/1.J052106.

${ }^{18}$ Deck, S. and Laraufie, R., "Numerical investigation of the ow dynamics past a three-element aerofoil," Journal of Fluid Mechanics, Vol. 732, 2013, pp. 401-444. doi: 10.1017/jfm.2013.363, Cambridge University Press 2013.

${ }^{19}$ Deck, S., Gand, F., Brunet, V., and Ben Khelil, S., "High-fidelity simulations of unsteady civil aircraft aerodynamics: stakes and perspectives. Application of zonal detached eddy simulation," Philosophical Transactions of the Royal Society A: Mathematical,Physical and Engineering Sciences, Vol. 372, No. 2022, 2014, pp. 1-21. doi: 10.1098/rsta.2013.0325.

${ }^{20}$ Chauvet, N., Deck, S., and Jacquin, L., "Zonal Detached Eddy Simulation of a Controlled Propulsive Jet," AIAA Journal, Vol. 45, No. 10, 2007, pp. 2458-2473. doi: 10.2514/1.28562.

${ }^{21}$ Gand, F., Brunet, V., and Mancel, G., "Zonal Detached Eddy Simulation (ZDES) Using Turbulent Inflow and High Order Schemes: Application to Jet Flows," Progress in Hybrid RANS-LES Modelling, edited by S. Girimaji, W. Haase, S.-H. Peng, and D. Schwamborn, Vol. 130 of Notes on Numerical Fluid Mechanics and Multidisciplinary Design, Springer International Publishing, 2015, pp. 141-152.

${ }^{22}$ Simon, F., Deck, S., Guillen, P., Cayzac, R., and Merlen, A., "Zonal-Detached-Eddy Simulation of Projectiles in the Subsonic and Transonic Regimes," AIAA Journal, Vol. 45, No. 7, 2007, pp. 1606-1619. doi: $10.2514 / 1.26827$.

${ }^{23}$ Deck, S., Renard, N., Laraufie, R., and Sagaut, P., "Zonal detached eddy simulation (ZDES) of a spatially developing flat plate turbulent boundary layer over the Reynolds number range $3150<\operatorname{Re} \theta<$ 14000," Physics of Fluids, Vol. 26, No. 2, 2014, pp. 025116. doi: http://dx.doi.org/10.1063/1.4866180.

${ }^{24}$ Riou, J. and Garnier, E., "Control of Separated Flow over Swept Missile Fin Using Pitching Oscillations," AIAA Journal, Vol. 49, 2011, pp. 1819-1822. doi: 10.2514/1.J051198.

${ }^{25}$ Weiss, P.-E. and Deck, S., "Control of the antisymmetric mode $(\mathrm{m}=1)$ for high Reynolds axisymmetric turbulent separating-reattaching flows," Physics of Fluids, Vol. 23, No. 095102, 2011, pp. 1-19. doi: 10.1063/1.3614481].

${ }^{26}$ Pain, R., Weiss, P.-E., and Deck, S., "Zonal Detached Eddy Simulation of the Flow Around a Simplified Launcher Afterbody," AIAA Journal, Vol. 52, No. 9, September 2014, pp. 1967-1979. doi: 10.2514/1.J052743.

${ }^{27}$ Le Pape, A., Richez, F., and Deck, S., "Zonal Detached-Eddy Simulation of an Airfoil in Poststall Condition," AIAA Journal, Vol. 51, 2013, pp. 1919-1931. doi: 10.2514/1.J052235.

${ }^{28}$ Richez, F. and Le Pape, A. and Costes, M., "Zonal Detached-Eddy Simulation of Separated Flow Around a Finite-Span Wing," AIAA Journal, Vol. 53, No. 11, 2015, pp. 3157-3166. doi: 10.2514/1.J053636.

${ }^{29}$ Deck, S., Renard, N., Laraufie, R., and Weiss, P.-E., "Large-scale contribution to mean wall shear stress in high-Reynolds-number flat-plate boundary layers up to Re $\theta=13650$," Journal of Fluid Mechanics, Vol. 743, 2014, pp. 202-248. doi: 10.1017/jfm.2013.629.

${ }^{30}$ Renard, N. and Deck, S., "Improvements in Zonal Detached Eddy Simulation for Wall Modeled Large Eddy Simulation," AIAA Journal, Vol. 53, No. 11, 2015, pp. 3499-3504. doi: 10.2514/1.J054143. 
${ }^{31}$ Chalot, F., Dagrau, F., Mallet, M., Normand, P., and Yser, P., "Higher-Order RANS and DES in an Industrial Stabilized Finite Element Code," IDIHOM: Industrialization of High-Order Methods - A TopDown Approach, edited by N. Kroll, C. Hirsch, F. Bassi, C. Johnston, and K. Hillewaert, Vol. 128 of Notes on Numerical Fluid Mechanics and Multidisciplinary Design, Springer International Publishing, 2015, pp. 489-519.

${ }^{32}$ Zhang, Y., Habashi, W. G., and Khurram, R. A., "Predicting wind-induced vibrations of high-rise buildings using unsteady $\{\mathrm{CFD}\}$ and modal analysis," Journal of Wind Engineering and Industrial Aerodynamics, Vol. 136, 2015, pp. 165 - 179. doi: http://dx.doi.org/10.1016/j.jweia.2014.11.008.

33Zhang, Y., Habashi, W. G., and Khurram, R. A., "Zonal Detached-Eddy Simulation of Turbulent Unsteady Flow over Iced Airfoils," Journal of Aircraft, 2015, pp. 1-14. doi: 10.2514/1.C033253.

${ }^{34}$ Terracol, M., Manoha, E., Murayama, M., and Yamamoto, K., "Aeroacoustic Calculations of the 30P30N High-lift Airfoil using Hybrid RANS/LES methods: Modeling and Grid Resolution Effects," 21st AIAA/CEAS Aeroacoustics Conference, AIAA Aviation, 2015.

${ }^{35}$ De La Puente, F., Sanders, L., Vuillot, F., and Manoha, E., "Nose landing gear flow and noise predictions on unstructured grid using a cell-centered Navier-Stokes code," 21st AIAA/CEAS Aeroacoustics Conference, AIAA Aviation, 2015.

${ }^{36}$ Rumsey, C. L., Smith, B. R., and Huang, G. P., "Description of a Website Resource for Turbulence Modeling Verification and Validation," 40th AIAA Fluid Dynamics Conference and Exhibit, June 28 July 1, Chicago, IL, AIAA-2010-4742, 2010.

${ }^{37}$ Yamada, K., Kikuta, H., Furukawa, M., Gunjishima, S., and Hara, Y., "Effects of tip clearance on the stall inception process in an axial compressor rotor," Proceedings of ASME Turbo Expo 2013: Turbine Technical Conference and Exposition GT2013, No. GT2013-95479, San Antonio, Texas, June 2013.

${ }^{38}$ Muthanna, C. and Devenport, W., "Wake of a Compressor Cascade with Tip Gap," AIAA Journal, Vol. 42, No. 11, Nov. 2004, pp. 2320. doi: 10.2514/1.5270.

${ }^{39}$ Wang, Y. and Devenport, W., "Wake of a Compressor Cascade with Tip Gap," AIAA Journal, Vol. 42, No. 11, Nov. 2004, pp. 2332. doi: 10.2514/1.5272.

${ }^{40}$ Shi, K. and Fu, S., "Study of shock/blade tip leakage vortex/boundary layer interaction in a transonic rotor with iddes method," Proceedings of ASME Turbo Expo 2013: Turbine Technical Conference and Exposition GT2013, No. GT2013-95252, San Antonio, Texas, June 2013.

${ }^{41}$ Shi, K., Xiao, Z., Chen, H., and Fu, S., "Numerical Study of Tip Leakage Flow of a Transonic Compressor Rotor with IDDES Method," Proceedings of the 21st ISABE Conference, Busan, Korea, No. ISABE-2013-1116, Sep. 9-13th 2013.

${ }^{42}$ Greschner, B. and Thiele, F., "Wall Modeled LES simulation of Rotor-Stator-Cascade Broadband Noise," 17th AIAA/CEAS Aeroacoustics Conference, No. 2873, Portland, June, 5-8 2011.

${ }^{43}$ Ottavy, X., Courtiade, N., and Gourdain, N., "Experimental and Computational Methods for Flow Investigation in High-Speed Multistage Compressor," Journal of Propulsion and Power, Vol. 28, No. 6, 2012, pp. 1141-1155. doi: 10.2514/1.60562.

${ }^{44}$ Touyeras, A. and Villain, M., "Aerodynamic design and test result analysis of a three stage research compressor," ASME Turbo Expo: Power for Land, Sea, and Air, Vienna, Austria, No. GT2004-53940, 2004, pp. $1-9$.

${ }^{45}$ Mersinligil, M., Brouckaert, J.-F., Courtiade, N., and Ottavy, X., "A High Temperature High Bandwidth Fast Response Total Pressure Probe for Measurements in a Multistage Axial Compressor," Journal of Engineering for Gas Turbines and Power, Vol. 134, No. 061601, 2012, pp. 11. doi: 10.1115/1.4006061. 
${ }^{46}$ Cambier, L., Heib, S., and Plot, S., "The Onera elsA CFD software: input from research and feedback from industry," Mechanics \& Industry, Vol. 14, 2013, pp. 159-174. doi: 10.1051/meca/2013056.

${ }^{47}$ Mary, I., Sagaut, P., and Deville, M., "An algorithm for low mach number unsteady flows," Computers E Fluids, Vol. 29, 2000, pp. 119-147. doi: 10.1016/S0045-7930(99)00007-9.

${ }^{48}$ Edwards, J. and Liou, M.-S., "Low diffusion flux-splitting methods for flows at all speeds," AIAA, Vol. 1862, 1997, pp. 261-271.

${ }^{49}$ Spalart, P. and Allmaras, S., "A one-equation turbulence model for aerodynamic flows," La Recherche Aérospatiale, Vol. 1, 1994, pp. 5-21.

${ }^{50}$ Daude, F., Méthode d'intégration temporelle implicite pour la simulation des grandes échelles application à la reduction du bruit de cavité, Ph.D. thesis, Université de Poitiers, Poitiers, 2007.

${ }^{51}$ Shur, M., Spalart, P., Strelets, K., and Travin, A., "Detached-eddy simulation of an airfoil at high angle of attack," Proceedings of the Fourth International Symposium on Engineering Turbulence Modelling and Measurements, edited by A. Elsevier, Vol. 4, Ajaccio, Corsica, 24-26 May 1999, pp. 669-678.

${ }^{52}$ Deck, S., Weiss, P.-E., Pamis, M., and Garnier, E., "Zonal Detached Eddy Simulation of a spatially developing at plate turbulent boundary layer," Computers \& Fluids, Vol. 48, 2011, pp. 1-15. doi: 10.1016/j.compuid.2011.03.009.

${ }^{53}$ Laraufie, R., Deck, S., and Sagaut, P., "A dynamic forcing method for unsteady turbulent inow conditions," Journal of Computational Physics, Vol. 230, 2011, pp. 86478663. doi: 10.1016/j.jcp.2011.08.012.

${ }^{54}$ Spalart, P., Deck, S., Shur, M., Squires, K., Strelets, K., and Travin, A., "A new version of detachededdy simulation, resistant to ambiguous grid densities," Theoretical And Computational Fluid Dynamics, Vol. 20, 2006, pp. 181-195. doi: 10.1007/s00162-006-0015-0.

${ }^{55}$ Spalart, P. and Shur, M., "On the sensitization of Turbulence Models to Rotation and Curvature," Aerospace Science and Technology, Vol. 5, 1997, pp. 297-302. doi: 10.1016/S1270-9638(97)90051-1.

${ }^{56}$ Tartousi, H., Kulisa, P., Leboeuf, F., Ngo Boum, G., Lefebvre, A., and Yammine, A., "Numerical Investigation of a Turbocharger Centrifugal Compressor: Volute Influence on the Performance of The Compressor," European Turbomachinery Conference, Istanbul, Turkey, March, 21-25 2011, pp. 1-10.

${ }^{57}$ Riéra, W., Castillon, L., Marty, J., and Leboeuf, F., "Inlet condition effects on the tip clearance flow with Zonal Detached Eddy Simulation," Journal of Turbomachinery, Vol. 136(4), No. 041018, April 2014, pp. 10. doi: 10.1115/1.4025216, Editor : R. Bunker.

${ }^{58}$ Denton, J., "Loss Mechanisms in Turbomachines," Journal of Turbomachinery, Vol. 115, 1993, pp. 621656. doi: 10.1115/1.2929299.

${ }^{59}$ Brion, V., Stabilité des paires de tourbillons contra-rotatifs : application au tourbillon de jeu dans les turbomachines, Ph.D. thesis, école Polytechnique, 2009.

${ }^{60}$ Ducros, F., Ferrand, V., Nicoud, F., Weber, C., Darracq, D., Gacherieu, C., and Poinsot, T., "LargeEddy Simulation of the Shock/Turbulence Interaction," Journal of Computational Physics, Vol. 152, 1999, pp. 517-549. doi: 10.1006/jcph.1999.6238.

${ }^{61}$ Hofmann, W. and Ballmann, J., "Shock-Vortex Interaction in a Transonic Turbocompressor," Contributions to the 13th STAB/DGLR Symposium Munich, Germany 2002, Vol. 87, 2004, pp. 458-466. doi: 10.1007/978-3-540-39604-8_57.

${ }^{62}$ Hunt, J. C. R., Wray, A., and Moin, P., "Eddies, stream, and convergence zones in turbulent flows," Tech. rep., Center for Turbulence Research Report CTR-S88, 1988. 
${ }^{63}$ Levy, Y., Degani, D., and Seginer, A., "Graphical visualization of vortical flows by means of helicity," AIAA Journal, Vol. 28, 1990, pp. 1347-1352. doi: 10.2514/3.25224.

${ }^{64}$ Gourdain, N. and Leboeuf, F., "Unsteady Simulation of an Axial Compressor Stage With Casing and Blade Passive Treatments," Journal of Turbomachinery, Vol. 131, 2009, pp. 12. doi: 10.1115/1.2988156.

${ }^{65}$ Sagaut, P. and Deck, S., "Large eddy simulation for aerodynamics: status and perspectives," Royal Society, Vol. 367, 2009, pp. 2849-2860. doi: 10.1098/rsta.2008.0269.

${ }^{66}$ Mersinligil, M., Brouckaert, J.-F., Courtiade, N., and Ottavy, X., "A High Temperature High Bandwidth Fast Response Total Pressure Probe for Measurements in a Multistage Axial Compressor," ASME Turbo Expo Power for Land Sea and Air, Vancouver, Canada,, No. 45558 in 2011, June 6-10 2011, pp. 1-24.

${ }^{67}$ Marty, J. and Aupoix, B., "Interaction of shrouded stator flow and main flow and its influence on performances of a three-stage high pressure compressor," Proceedings of the Institution of Mechanical Engineers Part A: Journal of Power and Energy, Vol. 226, June 2012, pp. 489-50. doi: 10.1177/0957650911414322.

${ }^{68}$ Méléard, S., Introduction à la théorie et au calcul des probabilités, École Polytechnique, 2010, ISBN $978 \quad 2 \quad 73021575$.

${ }^{69}$ Welch, P., "The Use of Fast Fourier Transform for the Estimation of Power Spectra: A Method Based on Time Averaging Over Short, Modified Periodograms," IEEE Transactions on audio and electroacoustics, Vol. 2, No. AU-15, 1967, pp. 70-73. 